\title{
The Magnetic Behaviour of CoTPP Supported on Coinage Metal Surfaces in the Presence of Small Molecules: A Molecular Cluster Study of the Surface trans-Effect
}

\author{
Silvia Carlotto ${ }^{1,2, *(\mathbb{D})}$, Iulia Cojocariu ${ }^{3}\left(\mathbb{D}\right.$, Vitaliy Feyer ${ }^{3,4}$, Luca Floreano $^{5}$ (D) and Maurizio Casarin $1,2, *(\mathbb{D}$ \\ 1 Dipartimento di Scienze Chimiche, Università degli Studi di Padova, Via Francesco Marzolo 1, \\ 35131 Padova, Italy \\ 2 Istituto di Chimica della Materia Condensata e di Tecnologie per l'Energia (ICMATE), Consiglio Nazionale \\ delle Ricerche (CNR) presso Dipartimento di Scienze Chimiche, Università degli Studi di Padova, Via F. \\ Marzolo 1, 35131 Padova, Italy \\ 3 Peter Grünberg Institute (PGI-6), Forschungszentrum Jülich GmbH, Leo-Brandt-Straße, \\ 52428 Jülich, Germany; i.cojocariu@fz-juelich.de (I.C.); v.feyer@fz-juelich.de (V.F.) \\ 4 Fakultät f. Physik and Center for Nanointegration Duisburg-Essen (CENIDE), Universität Duisburg-Essen, \\ D-47048 Duisburg, Germany \\ 5 Istituto Officina dei Materiali (IOM), Consiglio Nazionale delle Ricerche (CNR), Lab. TASC, S.S. 14, Km. 163,5, \\ 34149 Trieste, Italy; floreano@iom.cnr.it \\ * Correspondence: silvia.carlotto@unipd.it (S.C.); maurizio.casarin@unipd.it (M.C.)
}

\section{check for}

updates

Citation: Carlotto, S.; Cojocariu, I.;

Feyer, V.; Floreano, L.; Casarin, M.

The Magnetic Behaviour of CoTPP

Supported on Coinage Metal

Surfaces in the Presence of Small

Molecules: A Molecular Cluster

Study of the Surface trans-Effect.

Nanomaterials 2022, 12, 218. https://

doi.org/10.3390/nano12020218

Academic Editors: Francisco Torrens and Frederik Tielens

Received: 29 November 2021

Accepted: 8 January 2022

Published: 10 January 2022

Publisher's Note: MDPI stays neutral with regard to jurisdictional claims in published maps and institutional affiliations.

Copyright: (c) 2022 by the authors Licensee MDPI, Basel, Switzerland. This article is an open access article distributed under the terms and conditions of the Creative Commons Attribution (CC BY) license (https:/ / creativecommons.org/licenses/by/ $4.0 /)$.

\begin{abstract}
Density functional theory, combined with the molecular cluster model, has been used to investigate the surface trans-effect induced by the coordination of small molecules $\mathrm{L}(\mathrm{L}=\mathrm{CO}$, $\mathrm{NH}_{3}, \mathrm{NO}, \mathrm{NO}_{2}$ and $\mathrm{O}_{2}$ ) on the cobalt electronic structure of cobalt tetraphenylporphyrinato (CoTPP) surface-supported on coinage metal surfaces $(\mathrm{Cu}, \mathrm{Ag}$, and $\mathrm{Au})$. Regardless of whether L has a closedor an open-shell electronic structure, its coordination to Co takes out the direct interaction between $\mathrm{Co}$ and the substrate eventually present. The $\mathrm{CO}$ and $\mathrm{NH}_{3}$ bonding to CoTPP does not influence the Co local electronic structure, while the $\mathrm{NO}\left(\mathrm{NO}_{2}\right.$ and $\left.\mathrm{O}_{2}\right)$ coordination induces a Co reduction (oxidation), generating a $3 \mathrm{~d}^{8} \mathrm{Co}^{\mathrm{I}}\left(3 \mathrm{~d}^{6} \mathrm{Co}^{\mathrm{III}}\right)$ magnetically silent closed-shell species. Theoretical outcomes herein reported demonstrate that simple and computationally inexpensive models can be used not only to rationalize but also to predict the effects of the Co-L bonding on the magnetic behaviour of COTPP chemisorbed on coinage metals. The same model may be straightforwardly extended to other transition metals or coordinated molecules.
\end{abstract}

Keywords: density functional theory; transition metal porphyrinato complexes; molecular cluster model

\section{Introduction}

Transition metal porphyrinato (MP) and phthalocyaninato (MPc) complexes hold a prominent position among countless adsorbates because of their unique characteristics. Indeed, their conformational flexibility allows them to adopt different structural arrangements on diverse substrates, which may significantly influence their properties. Moreover, the metal centre occupying either the $\mathrm{P}^{2-}$ or the $\mathrm{Pc}^{2-}$ four-fold coordinative pocket often plays an active role in catalysis and sensors [1-7], while the $\mathrm{M} n \mathrm{~d}^{m}$ configuration drives the corresponding magnetic behaviour [8-11]. All these features make surface-supported MP and MPc appealing for technological applications, including chemical sensors [11,12], storage [13], spintronic/magnetic devices [14,15], and heterogenous catalysis $[12,16]$. With specific reference to spintronic applications, the ability to finely tune the adsorbate/substrate spin interaction is crucial and demands a detailed understanding of the interphase electronic properties. In this context, recent studies [17] have also shown that a chemical stimulus, such as the occupation of a $\mathrm{M}$ coordinative vacancy by a small 
molecule L, may be exploited to control the interphase magnetic properties by "switching on" / "switching off" the spin interactions between L, M, and the substrate (S) [18-22]. As such, the competition between the S-M and the M-L interactions has frequently been referred to as the surface spin-trans effect, or, more simply, as the trans-effect [23,24]. Per se, it is noteworthy that, even when dealing with the same MP/MPc surface-supported on the same $S$, diverse L may generate diverse magnetic behaviours [18-21,25]. A quantum mechanical modelling of the S-MP-L (S-MPc-L) interphase electronic properties might then be a promising alternative to an inefficient trial-and-error approach for designing new spintronic/magnetic devices [14,15].

In general, numerical experiments carried out by combining the density functional theory (DFT) with the supercell approximation (periodic DFT calculations) provide very accurate results, thus allowing for insights into the molecular, electronic, and magnetic properties of the surface-supported MP and MPc [25]. Nevertheless, a major drawback of such an approach concerns its computational cost, which may become prohibitive when several degrees of freedom are considered, or a defective surface is tackled. Magnetic properties of surface-supported MP and MPc are mainly associated with the M oxidation and spin states [26], i.e., with highly localized properties whose modelling within the molecular cluster approximation is not only computationally less demanding than the ordinary periodic model but also physically reasonable [27]. As a matter of fact, the molecular cluster model allows to look "into the changes in the local bonding situation at the metal centre upon coordination" and "has the advantage that a direct connection to molecular coordination chemistry can be made" [25].

The chemisorption of cobalt tetraphenylporphyrinato (CoTPP) on diverse metallic $S$ including $\mathrm{Ni}[23]$ and coinage metals ( $\mathrm{Cu}[26,28,29], \operatorname{Ag}[20,25,26,30,31], \mathrm{Au}[18,20,21,28,30])$ has been investigated in detail in the past. In this regard, it has been shown that both $\mathrm{Cu}$ and $\mathrm{Ag}$ surfaces act as electron donors, thus inducing a $\mathrm{Co}^{\mathrm{II}} \rightarrow \mathrm{Co}^{\mathrm{I}}$ pseudo reduction $[20,25,26,28,30,31]$, while the Au surface does not affect the Co oxidation state [18,20,21,32]. Even though a rationale for these evidences has been provided by periodic DFT numerical experiments $[18,21,25,26,29,33]$, it has been shown that less expensive calculations may adequately model experimental results ("switching on" / switching off" the spin interaction) $[15,17,25]$.

In this contribution, we present and discuss the outcomes of a series of DFT-based calculations, carried out by adopting the molecular cluster model to rationalize and hopefully predict the magnetic behaviour of CoTPP surface-supported on different metallic surfaces (Scheme 1), herein mimicked by a single atom (hereafter, MS; see below) and interacting at the same time with diverse $\mathrm{L}\left(\mathrm{L}=\mathrm{CO}, \mathrm{NH}_{3}, \mathrm{NO}, \mathrm{NO}_{2}\right.$ and $\mathrm{O}_{2}$, Scheme 1).

Even though, at first glance, the adopted model might be considered an oversimplification, it is useful to remind that Hieringer et al. [25] theoretically investigated the surface trans-effect of MPs (Co, Fe, $\mathrm{Zn}$ ) on $\mathrm{Ag}(111)$ by means of molecular cluster calculations run by attaching either a single $\mathrm{Ag}$ atom or a small cluster of varying size $\left(\mathrm{Ag}_{19}, \mathrm{Ag}_{72}\right)$ to the MP metal centre. The outcomes they obtained by exploiting diverse $\operatorname{Ag}_{n}(n=1,19$, 72) clusters as representative of the $\mathrm{Ag}(111)$ surface quantitatively differ; nevertheless, all of them perfectly agree about "the strong trans effect of NO on the interaction of CoTPP with the Ag substrate". The authors also emphasized that the adoption of the $\mathrm{Ag}_{19}$ or $\mathrm{Ag}_{72}$ clusters, besides been computationally more demanding, has " ... the drawback that an interpretation of the results is less straightforward than for the (NO)(Ag)MTPP models" [25]. 

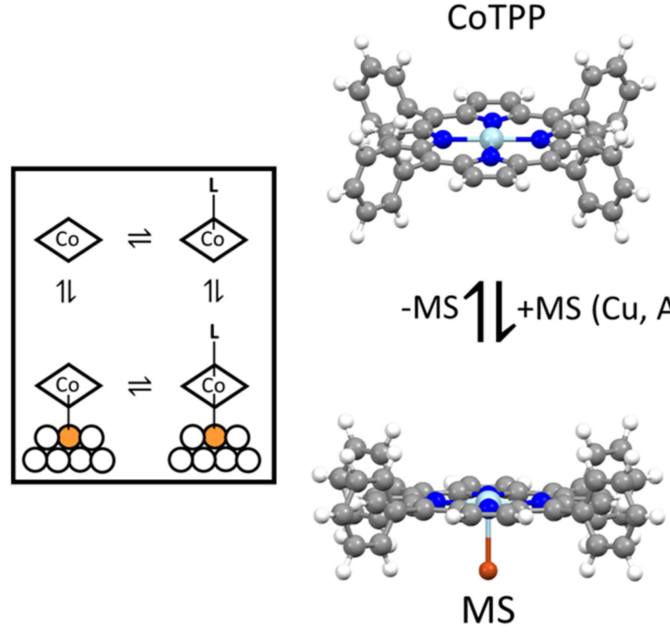

MS-COTPP
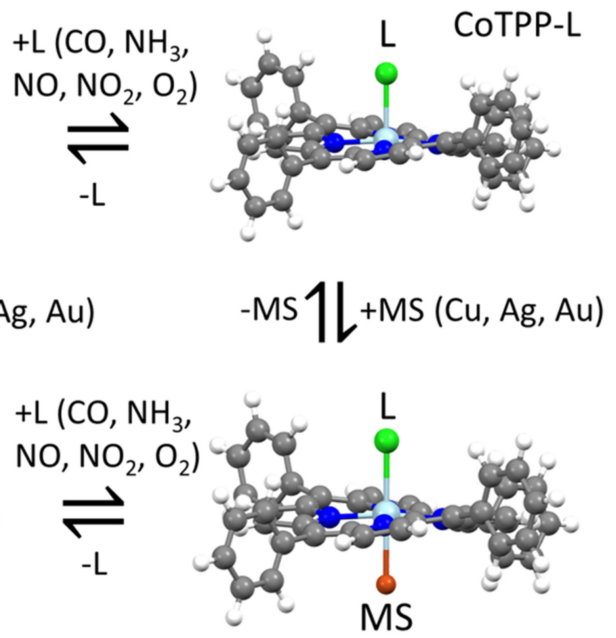

MS-COTPP-L

Scheme 1. A schematic representation of the molecular clusters adopted to model the S-CoTPP, the CoTPP-L, and the S-CoTPP-L interactions. Grey, white, blue, light blue, orange, and green spheres represent $\mathrm{C}, \mathrm{H}, \mathrm{N}, \mathrm{C}, \mathrm{MS}$, and the whole L molecule, respectively. A schematic sketch of isolated and interacting systems is reported in the inset.

\section{Computational Details}

Geometrical parameters of the adopted clusters have been optimized without any constraint by exploiting the Amsterdam Density Functional (ADF) suite of programs [34,35]. Scalar relativistic (SR) spin-restricted/spin-unrestricted calculations have been carried out by adopting the Zeroth Order Regular Approximation (ZORA [36,37]), by using the GGA functional BP86 [38,39], by employing a triple- $\zeta$ with one polarization function (TZP) Slater-type basis set [40] for all the atoms, and by freezing throughout the calculations the $\mathrm{C}, \mathrm{N}$, and $\mathrm{O} 1 \mathrm{~s}$ atomic orbital (AO), the $\mathrm{Co}$ and $\mathrm{Cu} 1 \mathrm{~s}-2 \mathrm{p}$ AOs, the $\mathrm{Ag} \mathrm{1s}-3 \mathrm{~d}$ AOs, and the $\mathrm{Au} 1 \mathrm{~s}-4 \mathrm{~d} \mathrm{AOs}$. Incidentally, the same computational set up has been successfully adopted to investigate the ground state properties of a quite large number of $\mathrm{M}$ complexes having either $\mathrm{Pc}^{2-}$ or $\mathrm{TPP}^{2-}$ as ligands $[15,17,41-45]$. 3D contour plots $(\mathrm{CPs})$ have also been obtained to acquire information about the localization and the character of the frontier MOs. Finally, bonding energies (BEs) have been analysed by means of Ziegler's extended transition state [46] method. According to this scheme, $B E$ s may be written as

$$
B E=-\left(\Delta E_{\mathrm{es}}+\Delta E_{\text {Pauli }}+\Delta E_{\text {orb }}+\Delta E_{\text {prep }}\right)
$$

where, $\Delta E_{\mathrm{es}}, \Delta E_{\text {Pauli }}$ and $\Delta E_{\text {orb }}$ represent contributions due to the pure electrostatic interaction, the Pauli repulsion (hereafter $\Delta E_{\mathrm{es}}+\Delta E_{\text {Pauli }}=\Delta E_{\mathrm{sr}}$, the steric repulsion), and the orbital interaction, respectively. The last term $\Delta E_{\text {prep }}$ provides information about the energy required to relax the geometrical structure of the CoTPP and L fragments to the geometry they assume in the final cluster. In this regard, it is noteworthy that atomic fragments from which a molecule/cluster is built must be spin-restricted [35]. Both MS-CoTPP and MSCoTPP-L $B E$ s have been then corrected by $\Delta E_{\mathrm{sp}}^{\mathrm{MS}}$, which corresponds to the $-\triangle B E$ between a spin-unrestricted and a spin-restricted atomic fragment. Amendments to $B E$ s due to the basis set superposition error have been systematically ignored as their contribution is known to be minute [47].

\section{Results and Discussion}

The competition between the S-Co and Co-L interactions, as well as its influence on the CoTPP magnetic properties, has been investigated by adopting the following three models: (i) MS-CoTPP ( $\mathrm{MS}=\mathrm{Cu}, \mathrm{Ag}, \mathrm{Au}$ ), representing the surface-supported CoTPP; (ii) CoTPP-L ( $\left.\mathrm{L}=\mathrm{CO}, \mathrm{NH}_{3}, \mathrm{NO}, \mathrm{NO}_{2}, \mathrm{O}_{2}\right)$, corresponding to the diverse adducts herein 
considered; and (iii) MS-CoTPP-L, representing the interphase generated by coordinating $\mathrm{L}$ to the surface-supported CoTPP. Optimized Cartesian coordinates of the free L molecules, of the free CoTPP complex, and of the MS-CoTPP, CoTPP-L, and MS-CoTPP-L clusters are reported in Tables S1-S29 of the Supplementary Materials (SM), while BEs and oxidation states for each molecule/adduct/cluster herein considered are collected in Tables S30-S38 of the SM.

\subsection{CoTPP on $\mathrm{Cu}, \mathrm{Ag}$ and $\mathrm{Au}$ Substrates}

The S-CoTPP interaction has been herein modelled by considering the direct interaction of $\mathrm{Co}$ with a single $\mathrm{Cu}, \mathrm{Ag}$, or $\mathrm{Au}$ atom, labelled MS (see Scheme 1). Even though perfectly aware that (i) CoTPP on $\operatorname{Ag}(111)$ occupies the surface hollow sites [48] and (ii) $\mathrm{CoP}$ [49] and $\mathrm{CuP}$ [50] on $\mathrm{Cu}(111)$ sit on the bridge sites, similarly to Hieringer et al. [25], who tested the $B E$ of CoTPP on diverse $\mathrm{Ag}$ chemisorption sites finding $B E$ minute variations, we decided to choose the on-top site for the sake of simplicity and to take full advantage of symmetry. As such, it is noteworthy that Buimaga-Iarinca and Morari [51] explored in great detail the effect of translation on the BE for MP adsorbed on $\mathrm{Ag}(111)$, finding a tiny energy dispersion $(0.1 \mathrm{eV})$ among the different adsorption sites.

The neutral $\mathrm{Cu}, \mathrm{Ag}$, and $\mathrm{Au}$ atoms have a $3 \mathrm{~d}^{10} 4 \mathrm{~s}^{1}, 4 \mathrm{~d}^{10} 5 \mathrm{~s}^{1}$, and $5 \mathrm{~d}^{10} 6 \mathrm{~s}^{1}$ electronic configuration, respectively, while the low-spin (LS) Co ${ }^{\mathrm{II}}$ species occupying the centre of the $\mathrm{TPP}^{2-}$ coordinative pocket carries a single unpaired electron in the Co $3 \mathrm{~d}_{\mathrm{z}^{2}}$-based molecular orbital (MO) [52]. Thus, the $\mathrm{C}_{4 \mathrm{v}}$ [53] MS-CoTPP cluster may have either 0 or 2 unpaired electrons. In the absence of any constraint on the MS-Co internuclear distance, the antiferromagnetic coupling between the two unpaired electrons is estimated to be significantly and systematically more stable than the ferromagnetic one by $0.71,0.87$, and $0.56 \mathrm{eV}$ for $\mathrm{MS}=\mathrm{Cu}, \mathrm{Ag}$, and $\mathrm{Au}$, respectively. Moreover, when relativistic effects are taken into account [54], the MS-Co internuclear distances and the MS-Co BEs corresponding to the spin-paired configuration (see Table S31 of the SM) have the well-known trend within the triad, thus indicating that, among the MS-CoTPP interactions, the Ag-CoTPP one is the weakest and most labile. Incidentally, MS-Co BEs amount to 1.17, 0.91, and $1.11 \mathrm{eV}$ for $\mathrm{MS}=\mathrm{Cu}, \mathrm{Ag}$, and $\mathrm{Au}$, respectively (see Table S31 of the SM).

Although of some interest to grasp the main features of the MS-CoTPP interaction, $B E$ s and internuclear distances are unable to rationalize the CoTPP "switch on" $\rightarrow$ "switch off" magnetism upon chemisorption on $\mathrm{Cu}[26,28,29,33]$ and $\mathrm{Ag}[20,25,26,30,31,33]$, as well as the absence of any CoTPP demagnetization upon chemisorption on $\mathrm{Au}[18,20,21,32,33]$. The thorough analysis of the MS-CoTPP frontier MOs turns out to be a Hobson's choice to obtain a rationale for the experimental trend. The MS-CoTPP interaction may be roughly described by a two-electrons/two-orbitals model involving the Co $3 \mathrm{~d}_{\mathrm{z}^{2}}$-based singly-occupied $\mathrm{MO}(\mathrm{SOMO})$ and the $\mathrm{MS}(n+1) \mathrm{s} \mathrm{AO}(n=4,5$, and 6 for $\mathrm{Cu}, \mathrm{Ag}$, and $\mathrm{Au}$, respectively). The analysis of their in-phase and out-of-phase combinations ( ${ }^{\mathrm{MS}-\mathrm{Co}_{\sigma}} \mathrm{and}$ MS-Co $\sigma^{*}$ in Figure 1) suggests that, upon chemisorption of CoTPP on $\mathrm{Cu}$ and $\mathrm{Ag}$, a Co $\mathrm{Co}_{+}^{\mathrm{II}}$ $\mathrm{MS}^{0} \rightarrow \mathrm{Co}^{\mathrm{I}}+\mathrm{MS}^{\mathrm{I}}$ pseudo redox reaction takes place (see Figure 1D). Consistently with the presence of a pseudo redox reaction involving a net $\mathrm{Cu}^{0} \rightarrow \mathrm{Co}^{\mathrm{II}} / \mathrm{Ag}^{0} \rightarrow \mathrm{Co}^{\mathrm{II}}$ charge transfer, the completely occupied ${ }^{\mathrm{Cu}-\mathrm{Co}} \sigma$ and ${ }^{\mathrm{Ag}-\mathrm{Co}_{\sigma}} \sigma$ combinations are mainly localized on the Co $3 \mathrm{~d}_{\mathrm{z}^{2}}$-based $\mathrm{MO}$, while the empty ${ }^{\mathrm{Cu}-\mathrm{Co}_{\sigma}{ }^{*}}$ and ${ }^{\mathrm{Ag}-\mathrm{Co}_{0}}{ }^{*}$ ones are strongly localized (>50\%) on the $\mathrm{Cu}_{4 \mathrm{~s}}$-based and the $\mathrm{Ag}_{5}$ s-based $\mathrm{MO}$, respectively. As such, it can be also useful to mention that the $\mathrm{Cu}$ and $\mathrm{Ag}$ Hirshfeld charges (Q) [55] of the Cu-CoTPP and Ag-CoTPP $\mathrm{C}_{4 \mathrm{v}}$ clusters amount to 0.19 and 0.24 , respectively (see Table S31 of the SM). Incidentally, the LS state foreseen by the molecular cluster model herein adopted and implying the presence of a pseudo $3 \mathrm{~d}^{8} \mathrm{Co}$ s species well agrees with DFT periodic calculations modelling the CoTPP chemisorption on $\mathrm{Cu}$ and Ag surfaces [20,25,26,28-31,33]. 


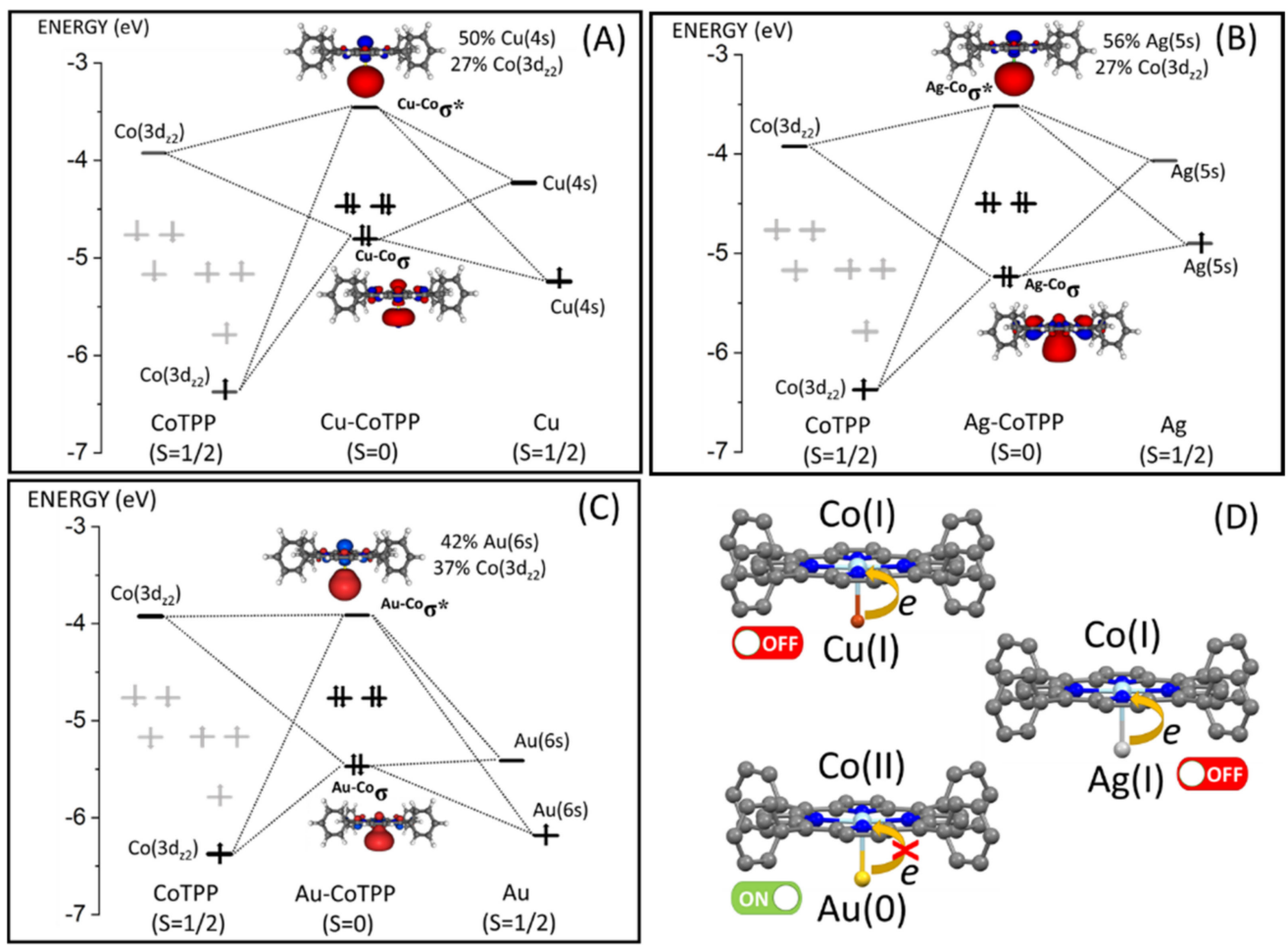

Figure 1. Correlation diagrams between CoTPP frontier energy levels and the $(n+1) \mathrm{s}$ MS AO of (A) Cu-CoTPP $(n=3),(\mathbf{B}) \operatorname{Ag}-\operatorname{CoTPP}(n=4)$, and (C) Au-CoTPP $(n=5) \mathrm{C}_{4 \mathrm{v}}$ clusters. The 3D plots of the in-phase and out-of-phase combinations between the Co $3 \mathrm{~d}_{\mathrm{z}} 2$-based MO and the MS $(n+1) \mathrm{s}$ AO are also displayed (isosurfaces correspond to $\pm 0.03 e^{1 / 2} \times \mathrm{A}^{-3 / 2}$ ). (D) Sketch of the different charge transfer behaviour along the triad. Colour codes are the same adopted in Scheme 1.

A change of scenery takes place when $\mathrm{MS}=\mathrm{Au}$; besides the comparable localization percentage of the ${ }^{\mathrm{Au}-\mathrm{Co}} \sigma^{*} \mathrm{MO}$ on the $\mathrm{Co} 3 \mathrm{~d}_{\mathrm{z}^{2}}$ and $\mathrm{Au} 6 \mathrm{~s} \mathrm{AOs}$ ( $37 \%$ and $42 \%$, respectively), the $\mathrm{Au}-\mathrm{CoTPP}{ }^{\mathrm{Au}} \mathrm{Q}$ is close to zero (0.05). In other words, no $\mathrm{Au}^{0} \rightarrow \mathrm{Co}^{\mathrm{II}}$ charge transfer able to "switch off" the CoTPP magnetization upon chemisorption on Au seems to be present $[18,21,32,33]$. In summary, the obtained results based on the molecular cluster model provide a rationale of the magnetic behaviour of CoTPP upon chemisorption on coinage metals. Notably, such an approach is undoubtedly simpler and computationally less expensive than periodic DFT calculations.

\subsection{CoTPP-L Adducts ( $\mathrm{L}=\mathrm{CO}, \mathrm{NH}_{3}, \mathrm{NO}, \mathrm{NO}_{2}, \mathrm{O}_{2}$ )}

The $\mathrm{L}$ selection has been determined by the presence in the literature of experimental and theoretical data pertaining to the CoTPP-L adducts $[24,25,33]$. The $\mathrm{L}$ herein considered may be divided in two groups according to their diamagnetic $\left(\mathrm{CO}\right.$ and $\mathrm{NH}_{3}$, hereafter ${ }^{0} \mathrm{~L}$ ) or paramagnetic (NO and $\mathrm{NO}_{2},{ }^{1} \mathrm{~L} ; \mathrm{O}_{2},{ }^{2} \mathrm{~L}$ ) nature, where the superscripts 0,1 , and 2 simply refer to the number of unpaired electrons carried by $\mathrm{L}$. The valence manifold of the CoTPP $-{ }^{0} \mathrm{~L}$ adducts is then unavoidably characterized by the presence of a single unpaired electron $[24,33]$ carried by $\mathrm{Co}^{\mathrm{II}}$, while the scenery may be more multifaceted when CoTPP $-{ }^{k} \mathrm{~L}$ adducts $(k=1$ or 2$)$ are considered.

Both $\mathrm{CO}$ and $\mathrm{NH}_{3}$ bind CoTPP vertically, C- and N-down oriented [33]; molecular cluster calculations have been then carried out by assuming a $\mathrm{C}_{4 \mathrm{v}}$ and a $\mathrm{C}_{\mathrm{s}}$ symmetry [53] for the CoTPP-CO and CoTPP- $\mathrm{NH}_{3}$ species, respectively (see Tables S10 and S11 of the $\mathrm{SM}$ ). CoTPP-CO and CoTPP- $\mathrm{NH}_{3} B E$ s, estimated according to Equation (1) are 0.33 and $0.28 \mathrm{eV}$, respectively, and are reported in Table S32 of the SM together with the optimized Co-D bond lengths (BLs, D corresponds to the L donor atom) and the Nalewajski-Mrozek $\left({ }^{\mathrm{NM}} \mathrm{I}_{\mathrm{Co}-\mathrm{D}}\right)$ bond multiplicity indexes [56-62]. In this regard, it can be useful to mention that the optimized $\mathrm{BL}_{\mathrm{C}-\mathrm{O}}$ passes from 1.139 to $1.157 \AA$ upon moving from the free molecule to 
the coordinated one, while both the $\mathrm{N}-\mathrm{H}$ BLs and the $\mathrm{H}-\hat{\mathrm{N}}-\mathrm{H}$ bond angles (BA) of the coordinated $\mathrm{NH}_{3}$ are negligibly affected upon coordination.

As expected and anticipated, the electronic structure analysis reveals that the ${ }^{0} \mathrm{~L}$ coordination to CoTPP does not determine any relevant charge transfer able to modify the $\mathrm{Co}^{\mathrm{II}}$ oxidation state $[24,33]$. In addition, the spin population analysis confirms that Co maintains its unpaired electron upon coordination, which remains localized on the Co-based 3d AOs (see Figure 2 and Figure S1 of the SM). Even though only two ${ }^{0} \mathrm{~L}$ have been herein considered, it appears likely that the ${ }^{0} \mathrm{~L}$ bonding to CoP-like and CoPc-like molecules cannot significantly perturb their magnetic properties.
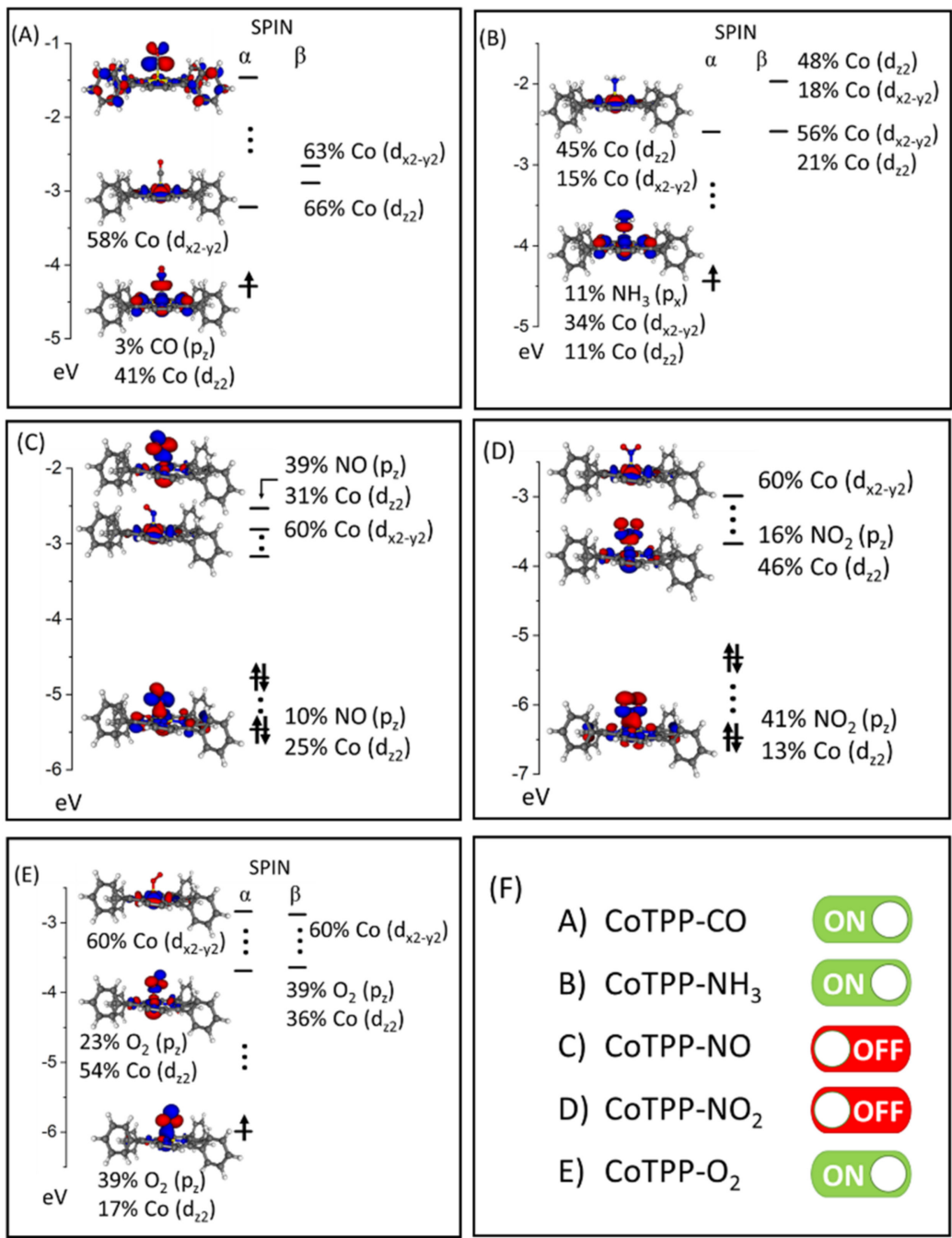

(F)
A) COTPP-CO

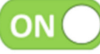
B) CoTPP- $-\mathrm{NH}_{3}$

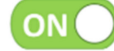
C) COTPP-NO
OOFF
D) COTPP-NO
OOFF
E) COTPP-O

Figure 2. Energy level diagrams of selected frontier MOs of (A) CoTPP-CO, (B) CoTPP$\mathrm{NH}_{3}$, (C) CoTPP-NO, (D) CoTPP- $\mathrm{NO}_{2}$, and (E) CoTPP-O ${ }_{2}$ (displayed isosurfaces correspond to $\left.\pm 0.03 e^{1 / 2} \times \mathrm{A}^{-3 / 2}\right)$. (F) Scheme of the "switch on"/"switch off" behaviour upon coordination of $\mathrm{L}$ to CoTPP. Vertical dots indicate that some levels, mainly localized on the TPP fragment, are omitted. Colour codes are the same adopted in Scheme 1.

Similarly to CoTPP- ${ }^{0} \mathrm{~L}$, the ${ }^{1} \mathrm{~L}$ coordination to CoTPP has been explored by taking advantage of the available experimental evidence [18]. In more detail, ADF calculations have been run by assuming a $\mathrm{N}$-down orientation for both $\mathrm{NO}$ and $\mathrm{NO}_{2}$ and by adopting a $\mathrm{C}_{\mathrm{s}}$ and a $\mathrm{C}_{2 \mathrm{v}}$ symmetry [53] for the CoTPP-NO and CoTPP- $\mathrm{NO}_{2}$ adducts, respectively ( $\mathrm{NO}$ and $\mathrm{NO}_{2} \mathrm{O}$ atoms point toward the meso $\mathrm{C}$ atoms of the macrocycle). Optimized geometries (see Tables S12 and S13 of the SM) and BEs have been evaluated for both LS (no unpaired electron) and high spin (HS, two unpaired electrons) states. 
Starting from CoTPP-NO, its diamagnetic state (the LS state is found to be $1.05 \mathrm{eV}$ more stable than the HS state) and the peculiar geometry of the $[\mathrm{CoNO}]^{8}$ fragment (the superscript 8 indicates the total number of electrons mostly localized on the Co $3 \mathrm{~d}$ and the NO $\pi^{*}$ orbitals) closely resemble the spin state and the crystal structure of the $[\mathrm{Co}(\mathrm{NO})(\mathrm{Salen})]$ adduct (Salen $=\mathrm{N}, \mathrm{N}^{\prime}$-bis(salicylidene)ethylenediamine) [63]. More specifically, the $\mathrm{Co}-$ $\hat{\mathrm{N}}$ - O BA is far from being linear both in CoTPP-NO $\left(122.5^{\circ}\right.$, see Table S33 of the SM) and in [Co(NO)(salen)] (127.0 [63]), the Co-N BLs are nearly identical (1.805 ^̊ in CoTPP-NO, see Table S33 of the SM, and $1.807 \AA$ in [Co(NO)(salen)] [63]), and the Co ${ }^{\mathrm{II}}$ species lies significantly above the plane passing through the donor atoms of the four-fold coordinative pocket $(0.19 \AA$ in CoTPP-NO and $0.25 \AA$ in [Co(NO)(salen)] [63]). Incidentally, the CoTPPNO highest occupied MO (the $76 \mathrm{a}^{\prime} \mathrm{HOMO}$ ) is strongly localized on the $\{\mathrm{CoNO}\}^{8}$ fragment $(66 \%)$, and it accounts for a bonding interaction, $\sigma$ in character (see Figure 2 and Figure S2 of the $\mathrm{SM}$ ), between the $\mathrm{NO}^{*}$, । MO and the Co 3d-based AOs lying in the $\mathrm{C}_{\mathrm{s}}$ symmetry plane, while the $51 \mathrm{a}^{\prime \prime}$ lowest unoccupied $\mathrm{MO}$ (LUMO) is reminiscent of the $\mathrm{NO}^{*}{ }_{\perp} \mathrm{MO}$ (see Figure S2 of the SM).

Despite all these similarities, the different behaviour of the $\{\mathrm{CoNO}\}^{8} \mathrm{~N}-\mathrm{O}$ BL upon moving from the free molecule to the coordinated one must be underlined. Theoretical results herein reported show a slight lengthening upon coordination (from 1.166 to $1.185 \AA$ ), while the experimental BL of the free $\mathrm{NO}(1.15 \AA)$ perfectly matches the [Co(NO)(salen)] one [63]. It is also worth noting that, even though the geometry of the $\{\mathrm{CoNO}\}^{8}$ fragment herein optimized fits very well the one obtained by Kim et al. for CoTPP-NO by means of periodic DFT calculations [64], their Co-NO BE $(1.67 \mathrm{eV})$ is higher than what we obtained by exploiting the molecular cluster model $(1.32 \mathrm{eV}$, see Table $\mathrm{S} 33$ of the $\mathrm{SM})$. This difference could be due to the different exchange-correlation potentials adopted in periodic (PBE [65]) and molecular cluster (BP86 [38,39]) numerical experiments. As a whole, our data indicate that: (i) the CoTPP-NO bonding is accompanied by the $\mathrm{Co}^{\mathrm{II}} \rightarrow \mathrm{Co}^{\mathrm{I}}$ "reduction"; (ii) the saddle conformation adopted by Kim et al. for the CoTPP-NO on $\mathrm{Au}(111)$ takes place independently of the surface presence; and (iii) if $\Delta E_{\text {prep }}^{\mathrm{NO}}(0.02 \mathrm{eV})$ and $\Delta E_{\text {prep }}^{\mathrm{CoTPP}}(0.21 \mathrm{eV})$ are both neglected, the $\mathrm{Co}-\mathrm{NO} B E$ is rather close to the value estimated by Kim et al. for the free CoTPP-NO [64].

Notwithstanding the lack of experimental evidence for the CoTPP- $\mathrm{NO}_{2}$ adduct, just under thirty years ago Rousseau et al. [66] tackled the electronic and molecular properties of the EPR silent CoPc- $\mathrm{NO}_{2}$ adduct, pointing out that the $\mathrm{Co}-\mathrm{N}_{\mathrm{NO} 2}$ direct interaction characterized by the Y-shaped coordination of $\mathrm{NO}_{2}$ to CoPc is accompanied by a $\mathrm{Co} \rightarrow \mathrm{NO}_{2}$ charge transfer able to affect the electronic density on the pyrrolic $\mathrm{N}$ atoms.

Analogously to CoTPP-NO, the CoTPP- $\mathrm{NO}_{2}$ diamagnetic state (LS) is found to be 0.91 $\mathrm{eV}$ more stable than the paramagnetic one; moreover, the optimized geometrical parameters of the $\mathrm{C}_{2 \mathrm{v}}$ CoTPP- $\mathrm{NO}_{2}$ adduct (see Table $\mathrm{S} 33$ of the $\mathrm{SM}$ ) are very close to those adopted by Rousseau et al. $\left(\mathrm{Co}-\mathrm{D}=1.91 \AA ; \mathrm{Co}-\hat{\mathrm{N}}-\mathrm{O}=120.0^{\circ}\right)$ [66] for their qualitative extended Hückel numerical experiments. As a result, the $\mathrm{NO}_{2}$ geometry changes upon coordination to CoTPP (the optimized N-O BL lengthens from 1.214 to $1.235 \AA$ and the $\mathrm{O}-\hat{\mathrm{N}}-\mathrm{O}$ BA narrows from $133.2^{\circ}$ to $125.3^{\circ}$ ) are perfectly in tune with the above-mentioned $\mathrm{Co} \rightarrow \mathrm{NO}_{2}$ charge transfer. Incidentally, the experimental $\mathrm{N}-\mathrm{O} B L$ and $\mathrm{O}-\hat{\mathrm{N}}-\mathrm{O}$ BA values pass from $1.197 \AA$ and $134.3^{\circ}$ in the free $\mathrm{NO}_{2}$ to $1.236 \AA$ and $115.4^{\circ}$ in the $\mathrm{NO}_{2}{ }^{-}$nitrite ion [67]. Considering the electronic properties of CoTPP- $\mathrm{NO}_{2}$, a thorough analysis of its frontier MOs (see Figure 2) reveals that, contrary to the Co-NO bonding, the $\mathrm{Co}-\mathrm{NO}_{2}$ one is accompanied by the $\mathrm{Co}^{\mathrm{II}} \rightarrow \mathrm{Co}^{\mathrm{III}}$ oxidation. In more detail, the CoTPP- $\mathrm{NO}_{2} 45 \mathrm{a}_{1} \mathrm{HOMO}$ is reminiscent of the ${ }^{\mathrm{NO} 2} \pi^{*}$ । SOMO [68] and it is poorly localized (9\%) on the Co $3 \mathrm{~d}-$ based AOs (see Figure 2D), while the $46 \mathrm{a}_{1}$ LUMO is strongly concentrated (46\%) on the Co $3 \mathrm{~d}_{\mathrm{z}^{2}} \mathrm{AO}$. As a whole, even though the coordination to CoTPP of both the ${ }^{1} \mathrm{~L}$ herein considered "switches off" the magnetization of the complex (no unpaired electron is present), the ${ }^{1} \mathrm{~L}$ quenching mechanism is opposite in $\mathrm{NO}$ and $\mathrm{NO}_{2}$ : in the former case, it implies the reduction of the $\mathrm{Co}^{\mathrm{II}}$ centre through the redox reaction $\mathrm{NO}+\mathrm{Co}^{\mathrm{II}} \rightarrow \mathrm{NO}^{+}$ 
$+\mathrm{Co}^{\mathrm{I}}$, while in the latter, the oxidation of the $\mathrm{Co}^{\mathrm{II}}$ centre through the redox reaction $\mathrm{NO}_{2}+\mathrm{Co}^{\mathrm{II}} \rightarrow \mathrm{NO}_{2}{ }^{-}+\mathrm{Co}^{\mathrm{III}}$ takes place.

$\mathrm{M}$ complexes with $\mathrm{O}_{2}$ as a ligand have attracted a great interest, mainly driven by the need of looking into the nature and strength of the bonding between dioxygen and $\mathrm{M}$ in proteins involved in the $\mathrm{O}_{2}$ carriage in living things. According to their nonlinear $\mathrm{M}-\left(\eta^{1}-\mathrm{O}-\mathrm{O}\right)$ or bridging $\mathrm{M}-\left(\mu-\mathrm{O}_{2}\right)$ configuration, the two main types of $1: 1 \mathrm{M}-\mathrm{O}_{2}$ complexes are usually labelled superoxo and peroxo [67]. Superoxo Co complexes are well structurally characterized [69-75] and $\mathrm{Co}-\left(\eta^{1}-\mathrm{O}_{2}\right)$ and $\mathrm{O}-\mathrm{O}$ BLs ( $\mathrm{Co}-\hat{\mathrm{O}}-\mathrm{O}$ BA) range

between $1.85-1.90$ and $1.25-1.35 \AA$, respectively $\left(115^{\circ}-125^{\circ}\right)$.

Numerical experiments herein reported have been limited to the superoxo configuration [18] for which both the HS (three unpaired electrons) and LS (one unpaired electron) states have been explored. Analogously to CoTPP ${ }^{1} \mathrm{~L}$, the LS state appears more stable than the HS one $(0.49 \mathrm{eV})$; moreover, the optimized $\mathrm{Co}-\left(\eta^{1}-\mathrm{O}_{2}\right) \mathrm{BL}$ and $\mathrm{Co}-\hat{\mathrm{O}}-\mathrm{O} \mathrm{BA}$ $\left(1.858 \AA\right.$ and $119.7^{\circ}$, see Table S34 of the SM) perfectly fall in the above reported ranges (the optimized O-O BLs in the free molecule and in the $\left(\eta^{1}-\mathrm{O}_{2}\right)$ species are 1.235 and $1.286 \AA$, respectively). A thorough analysis of the CoTPP- $\left(\eta^{1}-\mathrm{O}_{2}\right)$ electronic structure reveals that, similarly to CoTPP- $\mathrm{NO}_{2}$, the $\mathrm{Co}-\left(\eta^{1}-\mathrm{O}_{2}\right)$ bonding is accompanied by the $\mathrm{Co}^{\mathrm{II}} \rightarrow \mathrm{Co}{ }^{\mathrm{III}}$ oxidation with all but one spin orbitals reminiscent of the $\mathrm{O}_{2} \pi_{\mathrm{g}}$ MOs [67] (antibonding with respect to the $\mathrm{O}-\mathrm{O}$ interaction) occupied; the fourth, $\pi_{\mathrm{g}}$-like unoccupied $\mathrm{MO}(\mathrm{VMO})$ corresponds to the CoTPP- $\left(\eta^{1}-\mathrm{O}_{2}\right) 51 \mathrm{a}^{\prime \prime} \mathrm{LUMO}$, completely localized $(86 \%)$ on the spin down $(\downarrow)$ component of the $\pi_{\mathrm{g}}$ spin orbital $\perp$ to the symmetry plane (see Figure $2 \mathrm{E}$ ). Consistently with such a picture, the Co spin density is negligible, and the single unpaired electron is completely localized on $\mathrm{O}_{2}$ (see Figure $\mathrm{S} 3$ of the $\mathrm{SM}$ ). Interestingly, even though the number of unpaired electrons does not vary upon moving from CoTPP to CoTPP- $\left(\eta^{1}-\mathrm{O}_{2}\right)$ and no magnetization "switch off" is then expected (see Figure 2F), the spin configuration of the superoxo adduct is completely different from that of the pristine complex [33]. A summary of the oxidation state of the Co and L after the coordination is reported in Table S35 of the SM.

\subsection{CoTPP-L Adducts on Cu, Ag and Au Substrates: The Trans-Effect}

Theoretical results pertinent to the MS-CoTPP clusters and the CoTPP-L adducts confirm that simple, tiny, and computationally inexpensive models may be adopted to acquire information about the magnetic behaviour of CoTPP upon chemisorption on coinage metals as well as on perturbations induced by the coordination of ${ }^{k} \mathrm{~L}(k=0,1$, and 2 ) on the CoTPP frontier orbitals. The feasibility testing of the same approach to explore the effects induced at the same time by chemisorption and coordination on the CoTPP electronic structure is then challenging on one hand and appealing in terms of computational costs on the other hand. As a result, it may be useful to remember that, while both experimental and theoretical data are available in the literature, the latter studies have mostly been carried out by adopting periodic calculations $[18,19,21,23-25,33,76]$. Nature, symmetry, and strength of the surface trans-effect characterizing the different S-CoTPP-L interphases have been herein investigated by adopting the MS-CoTPP-L clusters, representative of the L interaction with CoTPP deposited on S. MS-CoTPP-L theoretical outcomes have been then compared with experimental and/or theoretical data from the literature, when available.

MS-CoTPP- ${ }^{0} \mathrm{~L}$ results have several common features for both the ${ }^{0} \mathrm{~L}$ herein considered, the most relevant being: (i) the MS-CoTPP-CO LS state (no unpaired electron) is more stable than the HS one (two unpaired electrons) by $0.58,0.52$, and $0.70 \mathrm{eV}$ for $\mathrm{MS}=\mathrm{Cu}$, $\mathrm{Ag}$ and $\mathrm{Au}$, respectively; (ii) similarly, the MS-CoTPP- $\mathrm{NH}_{3} \mathrm{LS}$ state is more stable than the $\mathrm{HS}$ one by $0.77,0.61$, and $0.82 \mathrm{eV}$ for $\mathrm{MS}=\mathrm{Cu}, \mathrm{Ag}$ and $\mathrm{Au}$, respectively; (iii) both the MS-Co and the Co-D BEs decrease upon moving from MS-CoTPP and CoTPP- ${ }^{0} \mathrm{~L}$ to MS-CoTPP- ${ }^{0} \mathrm{~L}$ for $\mathrm{Cu}$ and $\mathrm{Ag}$ (Tables S31, S32, S36, S37 of the SM); (iv) both the MS-Co and the Co-D BLs increase upon moving from MS-CoTPP and CoTPP- ${ }^{0} \mathrm{~L}$ to MS-CoTPP${ }^{0} \mathrm{~L}$ for $\mathrm{Cu}$ and $\mathrm{Ag}$ (Tables S31, S32, S36, S37 of the SM); and (v) the MS-Co interaction weakening induced by the ${ }^{0} \mathrm{~L}$ coordination is accompanied by the $\mathrm{MS}^{\mathrm{I}}+\mathrm{Co}^{\mathrm{I}} \rightarrow \mathrm{MS}^{0}+\mathrm{Co}^{\mathrm{II}}$ 
redox reaction for $\mathrm{MS}=\mathrm{Cu}$ and $\mathrm{Ag}$. Moreover, the MS-CoTPP_${ }^{0} \mathrm{~L}$ number of unpaired electrons (disregarding that localized on MS) mirrors the CoTPP_ ${ }^{0} \mathrm{~L}$ one. Incidentally, the doubly occupied MS-CoTPP-CO 30a 1 HOMO (MS = Cu and Ag) is strongly localized on the MS $(n+1) \mathrm{s} / n \mathrm{~d}_{\mathrm{z}^{2}}(n=3$ and 4 for $\mathrm{MS}=\mathrm{Cu}$ and $\mathrm{Ag}$, respectively) AOs and the Co $3 \mathrm{~d}_{\mathrm{z}^{2}} \mathrm{AO}$, while the doubly occupied MS-CoTPP-NH $374 \mathrm{a}^{\prime} \mathrm{HOMO}$ (MS = Cu and Ag) is strongly concentrated on the MS $(n+1) \mathrm{s} / n \mathrm{~d}_{\mathrm{z}^{2}} / n \mathrm{~d}_{\mathrm{x}^{2}-\mathrm{y}^{2}}(n=3$ and 4 for MS $=\mathrm{Cu}$ and $\mathrm{Ag}$, respectively) AOs and the Co $3 \mathrm{~d}_{\mathrm{z}^{2}} / 3 \mathrm{~d}_{\mathrm{x}^{2}-\mathrm{y}^{2}}$ AOs. Incidentally, MS-CoTPP-CO theoretical outcomes perfectly agree with experimental [76] and theoretical [33] data in the literature.

Even though Au-CoTPP_ ${ }^{0} \mathrm{~L}$ ADF results are also consistent with the presence of Co ${ }^{\mathrm{II}}$ $\left(3 d^{7}\right)$ and $A u^{0}\left(5 d^{10} 6 s^{1}\right)$ species, it must be remarked that no Co oxidation state variation takes place upon moving from $\mathrm{Au}-\mathrm{CoTPP}$ to $\mathrm{Au}-\mathrm{CoTPP}-{ }^{0} \mathrm{~L}$ : a consequence of the absence of any $\mathrm{Co}^{\mathrm{II}} \rightarrow \mathrm{Co}^{\mathrm{I}}$ reduction accompanying the chemisorption of CoTPP on Au. As such, it is noteworthy that the lengthening of the $\mathrm{Au}-\mathrm{Co}$ and $\mathrm{Co}-\mathrm{D}$ BLs upon the $\mathrm{L}$ coordination is less significant than that estimated for Cu-CoTPP-0 L and Ag-CoTPP-0 L (see Tables S31, $\mathrm{S} 32$ and S38). Molecular cluster results pertinent to $\mathrm{Au}-\mathrm{CoTPP}-\mathrm{NH}_{3}$ agree very well with experimental data and periodic calculations [18,21].

As a whole, the magnetization of the MS-CoTPP interphase (MS = Cu and Ag) is "switched on" by the ${ }^{0} \mathrm{~L}$ chemisorption, while no variation is expected on passing from $\mathrm{Au}-\mathrm{CoTPP}$ to Au-CoTPP-0 L (see Figure 3, third and fourth columns).

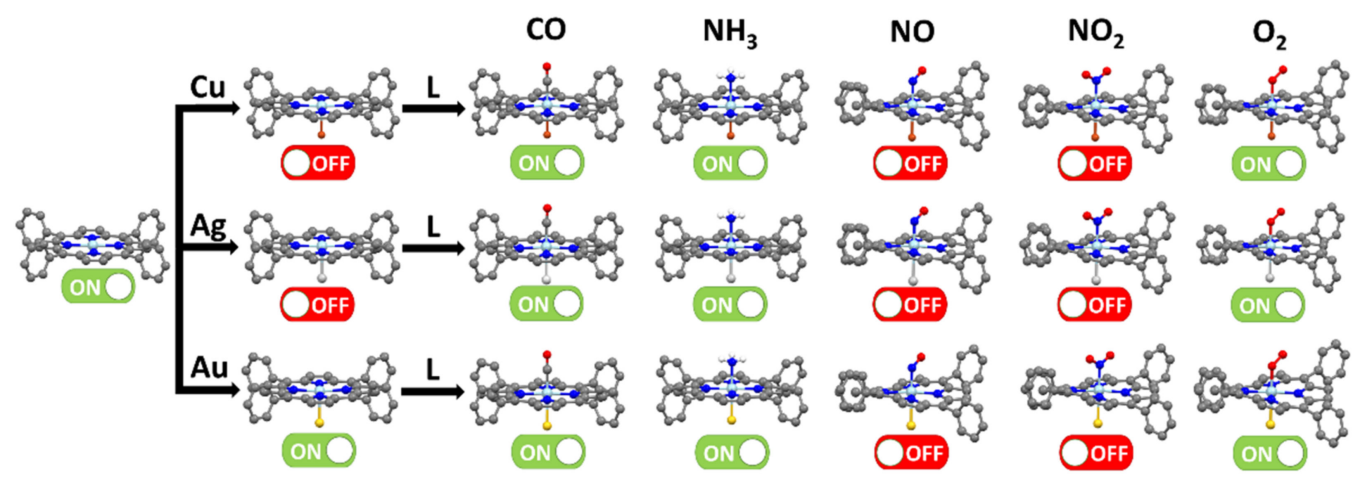

Figure 3. Schematic representation of the magnetic behavior ("switch on" /"switch off") of the free CoTPP (first column), MS-supported CoTPP ( $\mathrm{MS}=\mathrm{Cu}, \mathrm{Ag}$, and $\mathrm{Au}$; second column,) and MS-supported CoTPP interacting with $\mathrm{L}\left(\mathrm{L}=\mathrm{CO}, \mathrm{NH}_{3}, \mathrm{NO}_{2}, \mathrm{NO}\right.$, and $\mathrm{O}_{2}$; third—seventh columns).

Theoretical results obtained for the adducts CoTPP_ ${ }^{1} \mathrm{~L}$ and CoTPP_ ${ }^{2} \mathrm{~L}$ induce us to foresee that the electron exchange taking place at the S-CoTPP $-{ }^{k} \mathrm{~L}(k=1$ and 2$)$ interphases should not be limited to CoTPP and S, possibly involving ${ }^{1} \mathrm{~L}$ and ${ }^{2} \mathrm{~L}$ too. The inspection of Tables S35-S37 of the SM confirms this expectation and clearly shows that the strongest MSCoTPP $-{ }^{k} \mathrm{~L}$ trans-effect is associated to the NO coordination, whose presence: (i) decreases the $B E_{\mathrm{MS}-\mathrm{Co}_{\mathrm{o}}}(1.17 \rightarrow 0.41 \mathrm{eV}, 0.91 \rightarrow 0.26 \mathrm{eV}, 1.11 \rightarrow 0.49 \mathrm{eV}$, for $\mathrm{Cu}, \mathrm{Ag}$ and $\mathrm{Au}$, respectively); (ii) increases the $\mathrm{BL}_{\mathrm{MS}-\mathrm{Co}}(2.27 \rightarrow 2.36 \AA, 2.47 \rightarrow 2.60 \AA, 2.46 \rightarrow 2.56 \AA$, for $\mathrm{Cu}, \mathrm{Ag}$ and $\mathrm{Au}$, respectively). Further insights into the MS-Co and the Co-NO interactions may be gained by referring to Figure 4 , where MS-CoTPP $-{ }^{k} \mathrm{~L}(k=1,2)$ simplified energy level diagrams are displayed together with 3D plots of the MOs mainly localized on the MS-based $n \mathrm{~s}$ AO ( $n=4,5$ and 6 for $\mathrm{Cu}, \mathrm{Ag}$ and Au, respectively), the Co-based $3 \mathrm{~d}$ AOs, and the ${ }^{k} \mathrm{~L}-$ based $\pi^{*}$ fragment MOs. 


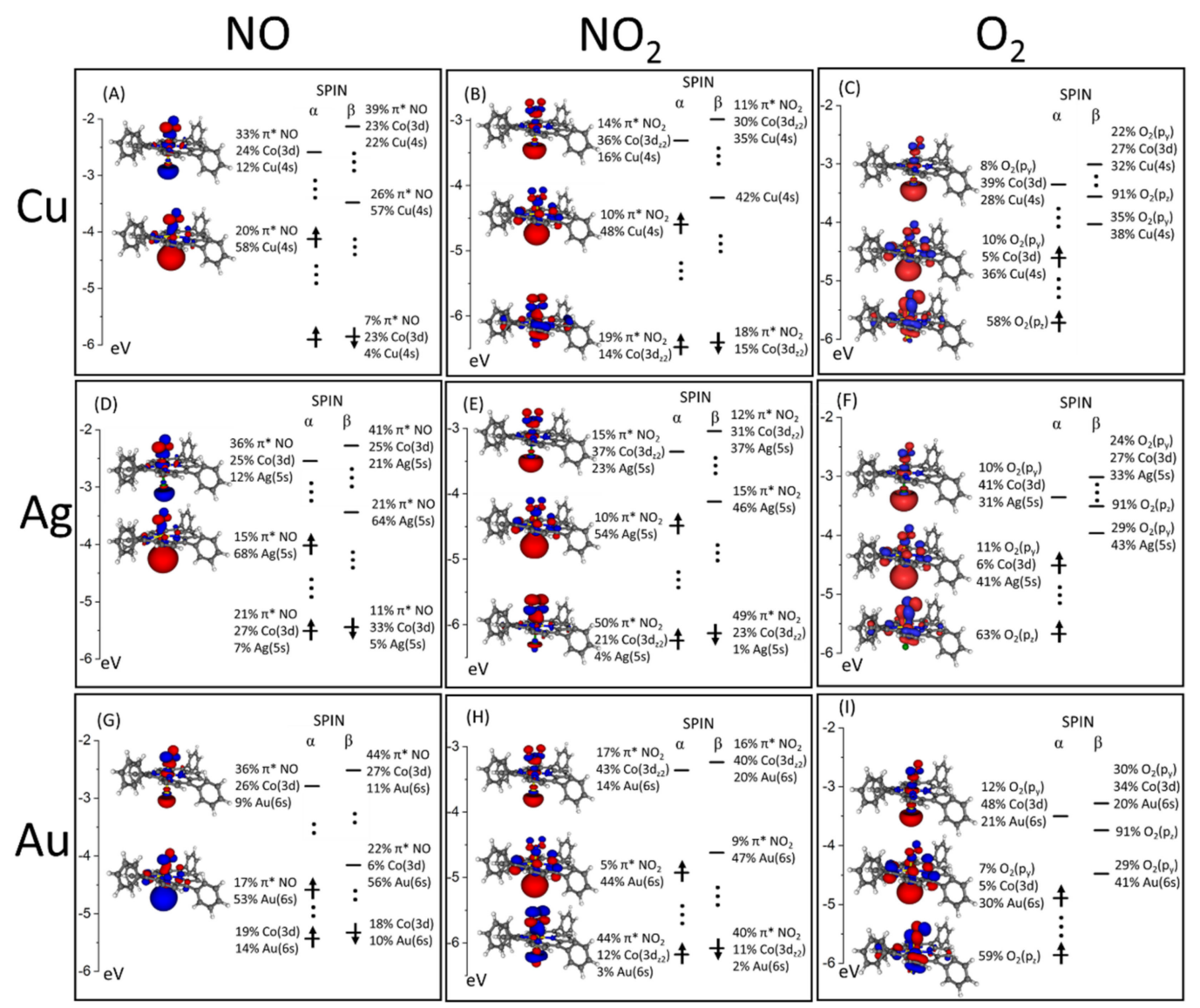

Figure 4. Energy level diagrams of selected frontier MOs of the MS-CoTPP-L clusters $((\mathbf{A}) \mathrm{MS}=\mathrm{Cu}$, $\mathrm{L}=\mathrm{NO} ;(\mathbf{B}) \mathrm{MS}=\mathrm{Cu}, \mathrm{L}=\mathrm{NO}_{2} ;(\mathbf{C}) \mathrm{MS}=\mathrm{Cu}, \mathrm{L}=\mathrm{O}_{2} ;(\mathbf{D}) \mathrm{MS}=\mathrm{Ag}, \mathrm{L}=\mathrm{NO} ;(\mathbf{E}) \mathrm{MS}=\mathrm{Ag}, \mathrm{L}=\mathrm{NO}_{2}$; (F) $\mathrm{MS}=\mathrm{Ag}, \mathrm{L}=\mathrm{O}_{2} ;(\mathbf{G}) \mathrm{MS}=\mathrm{Au}, \mathrm{L}=\mathrm{NO} ;(\mathbf{H}) \mathrm{MS}=\mathrm{Au}, \mathrm{L}=\mathrm{NO}_{2} ;(\mathbf{I}) \mathrm{MS}=\mathrm{Au}, \mathrm{L}=\mathrm{O}_{2}$; displayed isosurfaces of $3 \mathrm{D}$ plots correspond to $\left.\pm 0.03 e^{1 / 2} \times \AA^{-3 / 2}\right)$. The energy position of levels mainly localized on the TPP macrocycle is indicated by vertical dots.

The MO localization percentages reported in the figure testifies to the negligible perturbation induced by the MS presence on the $\mathrm{Co}-\mathrm{NO}$ bond; moreover, it is noteworthy that the MS $(n+1)$ s-based 83a' SOMO (MS $=\mathrm{Cu}, n=3$; $\mathrm{MS}=\mathrm{Ag}, n=4)$ has a negligible contribution $(\leq 2 \%)$ from the Co 3 d-based AOs. In addition, both the $\mathrm{NO}_{\pi^{*}}^{*}$-based ${ }^{\downarrow / \uparrow} 54 \mathrm{a}^{\prime \prime}$ and the $\mathrm{NO}_{\pi}^{*}$ । -based $\uparrow / \downarrow 85 \mathrm{a}^{\prime}$ MOs have a VMO character, and all but one (the $\downarrow / \uparrow 56 \mathrm{a}^{\prime \prime}$ MO) Co 3d-based MOs are completely occupied. The NO trans-effect is then characterized by the transfer of the ${ }^{1} \mathrm{~L}$ unpaired electron to the MS-CoTPP system, prompting Co and MS to assume a $3 \mathrm{~d}^{8}\left(\mathrm{Co}^{\mathrm{I}}\right)$ and a $n \mathrm{~d}^{10}(n+1) \mathrm{s}^{1}\left(\mathrm{Cu}^{0} / \mathrm{Ag}^{0}\right)$ electronic configuration and taking out, in agreement with periodic calculations [33], any direct MS-Co interaction. Altogether, theoretical outcomes clearly indicate that, even though both the Co oxidation state and its electronic configuration are nearly identical in MS-CoTPP, CoTPP-NO and MS-CoTPP-NO, the NO coordination to MS-CoTPP reduces MS ${ }^{\mathrm{I}}$ to its elemental oxidation state through the $\mathrm{NO} \rightarrow \mathrm{NO}^{+}$oxidation inhibiting at the same time any direct MS-Co bonding (see Tables S36 and S37). The NO coordination does not induce any "switch on" effect on MSCoTPP because the Co species does not vary its oxidation state and the ${ }^{1} \mathrm{~L}$ unpaired electron is used to reduce MS to its elemental oxidation state. It is noteworthy that both experimental studies and period calculations on S-CoTPP-NO support the molecular cluster outcomes herein reported [19,76].

The comparison of the Au-CoTPP-NO frontier electronic structure with those of the $\mathrm{Cu}-\mathrm{CoTPP}-\mathrm{NO}$ and $\mathrm{Ag}-\mathrm{CoTPP}-\mathrm{NO}$ molecular clusters clearly indicates that the different behavior of $\mathrm{Au}$ compared to $\mathrm{Cu}$ and $\mathrm{Ag}$ has, ultimately, to be traced back to the diverse MS-CoTPP interaction on passing from $\mathrm{Cu} / \mathrm{Ag}$ to $\mathrm{Au}$ (look at the second col- 
umn of Figure 3). Au preserves its $5 \mathrm{~d}^{10} 6 \mathrm{~s}^{1}$ electronic configuration along the whole $\mathrm{Au} \rightarrow \mathrm{Au}-\mathrm{CoTPP} \rightarrow \mathrm{Au}-\mathrm{CoTPP}-\mathrm{NO}$ path, while the $\mathrm{NO} \rightarrow \mathrm{NO}^{+}$oxidation (both the $\mathrm{NO}_{\pi}^{*}{ }_{\perp}$-based and the $\mathrm{NO}_{\pi}^{*}$, ।-based Au-CoTPP-NO MOs are empty) provides the electron needed for the $\mathrm{CO}^{\mathrm{II}} \rightarrow \mathrm{Co}^{\mathrm{I}}$ reduction. As a whole, the $\mathrm{NO}$ coordination to CoTPP chemisorbed on $\mathrm{Au}$ is expected to have a "switch off" effect due to the generation of a $\mathrm{Co}^{\mathrm{I}} 3 \mathrm{~d}^{8}$ closed shell (see Figure 3 ).

Although not as strong as that induced by the $\mathrm{NO}$ coordination, the $\mathrm{NO}_{2}$ trans-effect is quite effective too (see Tables S31, S33, S36-S38 of the SM); in particular, upon moving from MS-CoTPP and CoTPP-NO $\mathrm{NO}_{2}$ to MS-CoTPP-NO , the $B E_{\mathrm{MS}-\mathrm{Co}}$ and $B E_{\mathrm{Co}-\mathrm{D}}$ decreasing (see Tables S31, S33 and S36-S38) is accompanied by the BL ${ }_{M S-C o}$ and BL ${ }_{C o-D}$ increasing (see Tables S31, S33 and S36-S38). Common features of the MS-CoTPP-NO ${ }_{2}$ bonding scheme are: (i) the strong localization of the SOMO on the MS $(n+1)$ s AO (see Figure 4$)$, which is consistent with a MS $n \mathrm{~d}^{10}(n+1) \mathrm{s}^{1}$ elemental electronic configuration $(n=3,4,5$ for $\mathrm{MS}=\mathrm{Cu}, \mathrm{Ag}$, $\mathrm{Au}$, respectively); (ii) the $\mathrm{NO}_{2}$ "closed-shell" nature after coordination and then its "nitrite" character (see above); and (iii) the local "closed shell" electronic configuration $\left(3 \mathrm{~d}^{6}\right)$ of $\mathrm{Co}$ oxidized by $\mathrm{NO}_{2}$ to $\mathrm{Co}^{\mathrm{III}}$ (only the six $\mathrm{t}_{2 \mathrm{~g}}$-like Co-based spin orbitals \{the ${ }^{\uparrow / \downarrow} / 35 \mathrm{~b}_{1}, \uparrow / \downarrow 33 \mathrm{~b}_{2}, \uparrow / \downarrow 46 \mathrm{a}_{1}$ levels in Cu-CoTPP-NO ${ }_{2}$; the ${ }^{\uparrow / \downarrow} 35 \mathrm{~b}_{1}, \uparrow / \downarrow 33 \mathrm{~b}_{2}, \uparrow / \downarrow 48 \mathrm{a}_{1}$ levels in Ag-CoTPP-NO $\mathrm{N}_{2}$; the $\uparrow / \downarrow 35 \mathrm{~b}_{1}, \uparrow / \downarrow 37 \mathrm{~b}_{2}, \uparrow / \downarrow 50 \mathrm{a}_{1}$ levels in Au-CoTPP-NO $\mathrm{N}_{2}$ are occupied). Even though the MS-CoTPP- $\mathrm{NO}_{2}$ magnetic behaviour is closely reminiscent of the CoTPP- $\mathrm{NO}_{2}$ one (no "switch on" effect takes place upon chemisorption of $\mathrm{NO}_{2}$ ), it must be underlined that, similarly to MS-CoTPP-NO, the Au-CoTPP-NO $\mathrm{N}_{2}$ frontier electronic structure differs from the $\mathrm{Cu}-\mathrm{CoTPP}-\mathrm{NO}_{2}$ and $\mathrm{Ag}-\mathrm{CoTPP}-\mathrm{NO}_{2}$ ones as a consequence of the diverse MS-CoTPP interaction on passing from $\mathrm{Cu} / \mathrm{Ag}$ to $\mathrm{Au}$. The $\mathrm{NO}_{2}$ chemisorption on the Au-CoTPP species has then a "switch off" effect on the CoTPP magnetization. Once again, these results agree with experimental data and periodic calculations on Au-CoTPP-NO 2 [18,21].

Any attempt to optimize the geometry of the MS-CoTPP- $\left(\eta^{1}-\mathrm{O}_{2}\right)$ cluster with the LS configuration (no unpaired electrons) failed, while the HS (two unpaired electrons) geometry optimization converged rapidly and smoothly along the MS triad. Such a peculiar behaviour has to be traced back to the electron transfer processes involving at the same time the $\mathrm{Co}, \mathrm{MS}$, and $\mathrm{O}_{2}$ species (see below).

Aside from the expected decreases in $B E_{\mathrm{MS}-\mathrm{Co}_{\mathrm{o}}}$ and $B E_{\mathrm{Co}-\mathrm{O}}$, and the $\mathrm{BL}_{\mathrm{MS}-\mathrm{Co}_{\mathrm{o}}}$ and $\mathrm{BL}_{\mathrm{Co}-\mathrm{O}}$ increasing upon moving from MS-CoTPP and CoTPP- $\left(\eta^{1}-\mathrm{O}_{2}\right)$ to MS-CoTPP- $\left(\eta^{1}-\right.$ $\mathrm{O}_{2}$ ) (see Tables S31, S34, S36 and S37), a thorough analysis of the MS-CoTPP $-\left(\eta^{1}-\mathrm{O}_{2}\right)$ frontier electronic structure revealed: (i) the strong localization of the SOMO on the MS $(n+1)$ s AO (see Figure 4$)$, which is consistent with a MS $n \mathrm{~d}^{10}(n+1) \mathrm{s}^{1}$ elemental electronic configuration ( $n=3,4,5$ for $\mathrm{MS}=\mathrm{Cu}, \mathrm{Ag}, \mathrm{Au}$, respectively); (ii) the occupied character of all but one (the $\downarrow 54 a^{\prime \prime}$ level in $\mathrm{Cu}-\mathrm{CoTPP}-\left(\eta^{1}-\mathrm{O}_{2}\right)$ and $\mathrm{Ag}-\mathrm{CoTPP}-\left(\eta^{1}-\mathrm{O}_{2}\right)$; the $\downarrow 57 \mathrm{a}^{\prime \prime}$ level in $\left.\mathrm{Au}-\mathrm{CoTPP}-\left(\eta^{1}-\mathrm{O}_{2}\right)\right) \pi_{\mathrm{g}} \mathrm{O}_{2}$-based spin-orbitals (the ${ }^{\uparrow} 50 \mathrm{a}^{\prime \prime},{ }^{\uparrow} 77 \mathrm{a}^{\prime},{ }^{\downarrow} 81 \mathrm{a}^{\prime}, \downarrow 54 \mathrm{a}^{\prime \prime}$ levels in $\mathrm{Cu}-\mathrm{CoTPP}-\left(\eta^{1}-\mathrm{O}_{2}\right)$; the $\uparrow 52 \mathrm{a}^{\prime \prime}, \uparrow 79 \mathrm{a}^{\prime}, \downarrow 81 \mathrm{a}^{\prime}, \downarrow 54 \mathrm{a}^{\prime \prime}$ levels in Ag-CoTPP- $\left(\eta^{1}-\mathrm{O}_{2}\right)$; the $\uparrow 55 \mathrm{a}^{\prime \prime}$, $\uparrow 83 a^{\prime}, \downarrow 85 a^{\prime}, \downarrow 57 a^{\prime \prime}$ in Au-CoTPP- $\left.\left(\eta^{1}-\mathrm{O}_{2}\right)\right)$, thus indicating the superoxide nature of the coordinated $\mathrm{O}_{2}$; and (iii) the occupied character of only six (the ${ }^{\downarrow} 53 \mathrm{a}^{\prime \prime},{ }^{\uparrow} 54 \mathrm{a}^{\prime \prime},{ }^{\downarrow} 77 \mathrm{a}^{\prime}, \uparrow 78 \mathrm{a}^{\prime}$, $\uparrow / \downarrow 82 \mathrm{a}^{\prime}$ levels in Cu-CoTPP- $\left(\eta^{1}-\mathrm{O}_{2}\right)$, the $\downarrow 53 \mathrm{a}^{\prime \prime}, \uparrow 54 \mathrm{a}^{\prime \prime}, \downarrow 79 \mathrm{a}^{\prime}, \uparrow 80 \mathrm{a}^{\prime}, \uparrow / \downarrow 82 \mathrm{a}^{\prime}$ levels in Ag-

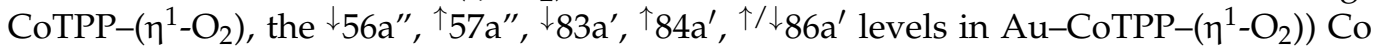
3d-based spin-orbitals, thus awarding a local "closed shell" electronic configuration $\left(3 \mathrm{~d}^{6}\right)$ to $\mathrm{Co}$, oxidized to $\mathrm{Co}^{\mathrm{III}}$, through the $\mathrm{O}_{2} \rightarrow \mathrm{O}_{2}{ }^{-}$reduction.

Even though the $\mathrm{O}_{2}$ coordination to CoTPP adsorbed on coinage metals should be accompanied by a magnetization "switch on" effect, it is noteworthy that unpaired electrons are localized on L rather than on Co (see Figure S3 of the SM). A summary of the oxidation state of the Co, L, and MS after the coordination is reported in Table S35.

\section{Conclusions}

A series of shared features binds the coordination of ${ }^{k} \mathrm{~L}$ to CoTPP molecule supported on coinage metal surfaces: (i) both $B E_{\mathrm{MS}-\mathrm{Co}_{\mathrm{O}}}$ and $B E_{\mathrm{Co}_{\mathrm{O}} \mathrm{D}}\left(\mathrm{BL}_{\mathrm{MS}-\mathrm{Co}_{\mathrm{o}}}\right.$ and $\left.\mathrm{BL}_{\mathrm{Co}-\mathrm{D}}\right)$ decrease 
(increase) upon moving from MS-CoTPP and CoTPP-L to MS-CoTPP-L; (ii) the MS oxidation state in the MS-CoTPP-L cluster is systematically found equal to 0; (iii) the local electronic structure of the CoTPP-L fragment in the MS-CoTPP-L cluster is very similar to that of the COTPP-L adducts; and (iv) the different MS-CoTPP-L BE $E_{\mathrm{Co}-\mathrm{D}}$ values are scarcely affected by MS, thus confirming the leading role played by the trans-coordinate ligand in the weakening of the direct MS-Co bonding. As a whole, the results presented and discussed herein demonstrate that small and computationally inexpensive molecular clusters can be used to confidently predict the influence of different ligands on the surface chemical bonds of adsorbed metalloporphyrins on diverse coinage metals and then be exploited to drive experiments towards the desired outcomes.

Supplementary Materials: The following supporting information can be downloaded at: https: / / www.mdpi.com/article/10.3390/nano12020218/s1. Figure S1: 3D plot of the CoTPP-CO spin density. The displayed isosurface corresponds to $+0.005 e \times \AA^{-3}$ value; Figure S2: 3D plot of the CoTPP-NO 76a' HOMO (left panel) and 51a" LUMO (right panel). The displayed isosurfaces correspond to $\pm 0.03 e^{1 / 2} \times \AA^{-3 / 2}$ values; Figure S3: 3D plot of the CoTPP $-\left(\eta^{1}-\mathrm{O}_{2}\right)$ spin density. The displayed isosurface corresponds to $+0.005 e \times \AA^{-3}$ value; Table S1: Optimized coordinates $(\AA)$ of the free CO $\left(\mathrm{C}_{\infty \mathrm{v}}\right)$ at the SR-ZORA, BP86, TZP, spin-restricted level of theory; Table S2: Optimized coordinates $(\AA)$ of the free $\mathrm{NH}_{3}\left(\mathrm{C}_{3 \mathrm{v}}\right)$ at the SR-ZORA, BP86, TZP, spin-restricted level of theory; Table S3: Optimized coordinates $(\AA)$ of the free NO $\left(\mathrm{C}_{\infty \mathrm{v}}\right)$ at the SR-ZORA, BP86, TZP, spin-unrestricted level of theory; Table S4: Optimized coordinates $(\AA)$ of the free $\mathrm{NO}_{2}\left(\mathrm{C}_{2 \mathrm{v}}\right)$ at the SRZORA, BP86, TZP, spin-unrestricted level of theory; Table S5: Optimized coordinates $(\AA)$ of the free $\mathrm{O}_{2}$ $\left(\mathrm{D}_{\infty \mathrm{h}}\right)$ at the SR-ZORA, BP86, TZP, spin-unrestricted level of theory; Table S6: Optimized coordinates (A) of the low spin (LS) CoTPP complex $\left(\mathrm{D}_{4 \mathrm{~h}}\right)$ at the SR-ZORA, BP86, TZP, spin-unrestricted level of theory; Table S7: Optimized coordinates $(\AA)$ of the LS Cu-CoTPP cluster $\left(\mathrm{C}_{4 \mathrm{v}}\right)$ at the SR-ZORA, BP86, TZP, spin-restricted level of theory; Table S8: Optimized coordinates ( $\mathrm{A})$ of the LS Ag-CoTPP cluster $\left(\mathrm{C}_{4 \mathrm{v}}\right)$ at the SR-ZORA, BP86, TZP, spin-restricted level of theory; Table S9: Optimized coordinates $(\AA)$ of the LS Au-CoTPP cluster $\left(\mathrm{C}_{4 \mathrm{v}}\right)$ at the SR-ZORA, BP86, TZP, spin-restricted level of theory; Table S10: Optimized coordinates $(\AA)$ of the LS CoTPP-CO adduct $\left(\mathrm{C}_{4 \mathrm{v}}\right)$ at the SR-ZORA, BP86, TZP, spin-unrestricted level of theory; Table S11: Optimized coordinates ( $\AA$ ) of the LS CoTPP-NH $\mathrm{N}_{3}$ adduct $\left(\mathrm{C}_{\mathrm{s}}\right)$ at the SR-ZORA, BP86, TZP, spin-unrestricted level of theory; Table S12: Optimized coordinates $(\AA)$ of the LS CoTPP-NO adduct $\left(\mathrm{C}_{\mathrm{s}}\right)$ at the SR-ZORA, BP86, TZP, spin-restricted level of theory; Table S13: Optimized coordinates $(\AA)$ of the LS CoTPP- $\mathrm{NO}_{2}$ adduct $\left(\mathrm{C}_{2 \mathrm{v}}\right)$ at the SR-ZORA, BP86, TZP, spin-restricted level of theory; Table S14: Optimized coordinates $(\AA)$ of the LS CoTPP-O $\mathrm{O}_{2}$ adduct $\left(\mathrm{C}_{\mathrm{s}}\right)$ at the SR-ZORA, BP86, TZP, spin-unrestricted level of theory; Table S15: Optimized coordinates (A) of the LS Cu-CoTPP-CO cluster $\left(\mathrm{C}_{4 \mathrm{v}}\right)$ at the SR-ZORA, BP86, TZP, spin-restricted level of theory; Table S16: Optimized coordinates $(\AA)$ of the LS Ag-CoTPP-CO cluster $\left(\mathrm{C}_{4 \mathrm{v}}\right)$ at the SR-ZORA, BP86, TZP, spin-restricted level of theory; Table S17: Optimized coordinates ( $)$ of the LS Au-CoTPP-CO cluster $\left(\mathrm{C}_{4 \mathrm{v}}\right)$ at the SR-ZORA, BP86, TZP, spin-restricted level of theory; Table S18: Optimized coordinates $(\AA)$ of the LS Cu-CoTPP-NH ${ }_{3}\left(C_{s}\right)$ cluster at the SR-ZORA, BP86, TZP, spin-restricted level of theory; Table S19: Optimized coordinates ( $⿱$ ) of the LS Ag-CoTPP- $\mathrm{NH}_{3}\left(\mathrm{C}_{\mathrm{s}}\right)$ cluster at the SR-ZORA, BP86, TZP, spin-restricted level of theory; Table S20: Optimized coordinates (A) of the LS Au-CoTPP$\mathrm{NH}_{3}\left(C_{\mathrm{S}}\right)$ cluster at the SR-ZORA, BP86, TZP, spin-restricted level of theory; Table S21: Optimized coordinates $(\AA)$ of the LS Cu-CoTPP-NO $\left(\mathrm{C}_{\mathrm{s}}\right)$ cluster at the SR-ZORA, BP86, TZP, spin-unrestricted level of theory; Table S22: Optimized coordinates $(\AA)$ of the LS Ag-CoTPP-NO $\left(\mathrm{C}_{\mathrm{S}}\right)$ cluster at the SR-ZORA, BP86, TZP, spin-unrestricted level of theory; Table S23: Optimized coordinates $(\AA)$ of the LS Au-CoTPP-NO $\left(\mathrm{C}_{\mathrm{S}}\right)$ cluster at the SR-ZORA, BP86, TZP, spin-unrestricted level of theory; Table S24: Optimized coordinates $(\AA)$ of the LS Cu-CoTPP-NO $\left(\mathrm{C}_{2 \mathrm{v}}\right)$ cluster at the SR-ZORA, BP86, TZP, spin-unrestricted level of theory; Table S25: Optimized coordinates $(\AA)$ of the LS Ag-CoTPP-NO $\left(\mathrm{C}_{2 \mathrm{v}}\right)$ cluster at the SR-ZORA, BP86, TZP, spin-unrestricted level of theory; Table S26: Optimized coordinates $(\AA)$ of the LS Au-CoTPP- $\mathrm{NO}_{2}\left(\mathrm{C}_{2 \mathrm{v}}\right)$ cluster at the SR-ZORA, BP86, TZP, spin-unrestricted level of theory; Table S27: Optimized coordinates $(\AA)$ of the high spin $(\mathrm{HS}) \mathrm{Cu}-\mathrm{CoTPP}-\mathrm{O}_{2}\left(\mathrm{C}_{\mathrm{s}}\right)$ cluster at the SR-ZORA, BP86, TZP, spin-unrestricted level of theory; Table S28: Optimized coordinates $(\AA)$ of the HS Ag-CoTPP- $\mathrm{O}_{2}\left(\mathrm{C}_{\mathrm{s}}\right)$ cluster at the SR-ZORA, BP86, TZP, spin-unrestricted level of theory; Table S29: Optimized coordinates ( $\AA$ ) of the HS Au-CoTPP- $\mathrm{O}_{2}\left(\mathrm{C}_{\mathrm{S}}\right)$ cluster at the SR-ZORA, BP86, TZP, spin-unrestricted level of theory; Table S30: Co Hirshfeld's charge $\left(\mathrm{Q}_{\mathrm{Co}}, e\right)$; CoTPP, single atoms 
and small molecules $B E$ s and $\Delta E_{s p}^{\mathrm{MS}}(\mathrm{MS}=\mathrm{Cu}, \mathrm{Ag}, \mathrm{Au})$; all the energy terms are in eV; Table S31: $\mathrm{Q}_{\mathrm{Co}}$ (e) and $\mathrm{Q}_{\mathrm{MS}}(e)$ of the MS-CoTPP clusters; MS-Co bond lengths (BL, $\AA$ ); MS-CoTPP BEs, CoTPP preparation energies $\left(\Delta E_{\mathrm{prep}}^{\mathrm{CoTPP}}\right), \Delta E_{\mathrm{sp}}^{\mathrm{MS}}$ (see Table S30) and $B E s$ of the MS-Co bond; all the energy terms are in eV; Table S32: $\mathrm{Q}_{\mathrm{Co}}(e)$ and $\mathrm{Q}_{0_{\mathrm{L}}}(e)$ of the LS CoTPP- ${ }^{0} \mathrm{~L}$ adducts; Nalewajski-Mrozek $\left({ }^{\mathrm{NM}} \mathrm{I}_{\mathrm{Co}-\mathrm{D}}\right)^{\mathrm{a}}$ indexes; Co-D BL $(\AA) ; \Delta E_{\text {prep }}^{\mathrm{CoTPP}}, \Delta E_{\text {prep }}^{0_{\mathrm{L}}}$ and BEs of the CoTPP- ${ }^{0} \mathrm{~L}$ adducts and of the Co-D bond; all the energy terms are in $\mathrm{eV}$; Table S33: $\mathrm{Q}_{\mathrm{Co}}(e)$ and $\mathrm{Q}_{1_{\mathrm{L}}}(e)$ of the LS CoTPP- ${ }^{1} \mathrm{~L}$ adducts; ${ }^{\mathrm{NM}} \mathrm{I}_{\mathrm{Co}-\mathrm{D}}$ indexes; Co-D BL $(\AA) ; \Delta E_{\text {prep }}^{\mathrm{CoTPP}}, \Delta E_{\text {prep }}^{1_{\mathrm{L}}}$ and BEs of the CoTPP_ ${ }^{1} \mathrm{~L}$ adducts and of the Co-D bond; all the energy terms are in eV; Table S34: $\mathrm{Q}_{\mathrm{Co}}(e)$ and $\mathrm{Q}_{\mathrm{2}_{\mathrm{L}}}(e)$ of the LS CoTPP_${ }^{2} \mathrm{~L}$ adduct; ${ }^{\mathrm{NM}} \mathrm{I}_{\mathrm{Co}-\mathrm{O}}$ indexes; Co-O BL $(\AA) ; \Delta E_{\text {prep }}^{\mathrm{CoTPP}}, \Delta E_{\text {prep }}^{2 \mathrm{~L}}, B E$ s of the CoTPP- ${ }^{2} \mathrm{~L}$ adduct and of the Co- ${ }^{2} \mathrm{~L}$ bond; all the energy terms are in $\mathrm{eV}$; Table S35: Co, MS and $\mathrm{L}$ formal oxidation states in the free CoTPP complex and in the MS-CoTPP, CoTPP-L, and MS-CoTPP-L clusters; Table S36: $\mathrm{Q}_{\mathrm{Co}}(e), \mathrm{Q}_{\mathrm{Cu}}(e)$ and $\mathrm{Q}_{\mathrm{L}}(e)$ of the $\mathrm{Cu}-\mathrm{CoTPP}-\mathrm{L}$ clusters; ${ }^{\mathrm{NM}} \mathrm{I}_{\mathrm{Cu}-\mathrm{Co}}$ and ${ }^{\mathrm{NM}} \mathrm{I}_{\mathrm{Co}-\mathrm{D}}$ indexes; ${ }^{\mathrm{a}} \mathrm{Co}-\mathrm{D}$ BLs $(\AA) ;{ }^{\mathrm{a}} \Delta E_{\text {prep }}^{\mathrm{CoTPP}-\mathrm{L}}$, $\Delta E_{\text {prep }}^{\mathrm{Cu}-\mathrm{CoTPP}}, \Delta E_{\text {prep }}^{\mathrm{L}}, B E$ s of the Cu-CoTPP-L clusters and of the Co-L and Cu-Co bonds; all the energy terms are in eV; Table S37: $\mathrm{Q}_{\mathrm{Co}}(e), \mathrm{Q}_{\mathrm{Ag}}(e)$ and $\mathrm{Q}_{\mathrm{L}}(e)$ of $\mathrm{Ag}-\mathrm{CoTPP}-\mathrm{L}$ clusters; ${ }^{\mathrm{NM}} \mathrm{I}_{\mathrm{Ag}-\mathrm{Co}}$ and ${ }^{\mathrm{NM}} \mathrm{I}_{\mathrm{Co}-\mathrm{D}}$ indexes; Co-D BLs $(\AA) ; \Delta E_{\text {prep }}^{\mathrm{CoTPP}-\mathrm{L}}, \Delta E_{\text {prep }}^{\mathrm{Ag}-\mathrm{CoTPP}}, \Delta E_{\text {prep }}^{\mathrm{L}}, B E$ s of the Ag-CoTPP-L clusters and of the $\mathrm{Co}-\mathrm{L}$ and $\mathrm{Ag}-\mathrm{Co}$ bonds; all the energy terms are in $\mathrm{eV}$; Table S38: $\mathrm{Q}_{\mathrm{Co}}(e), \mathrm{Q}_{\mathrm{Au}}(e)$ and $\mathrm{Q}_{\mathrm{L}}$ (e) of Au-CoTPP-L clusters; ${ }^{\mathrm{NM}} \mathrm{I}_{\mathrm{Au}-\mathrm{Co}}$ and ${ }^{\mathrm{NM}} \mathrm{I}_{\mathrm{Ag}-\mathrm{D}}$ indexes; Co-D BLs $(\AA) ; \Delta E_{\text {prep }}^{\mathrm{CoTP}-\mathrm{L}}, \Delta E_{\text {prep }}^{\mathrm{Au}-\mathrm{CoTPP}}$, $\Delta E_{\text {prep }}^{\mathrm{L}}, B E \mathrm{~s}$ of the $\mathrm{Au}-\mathrm{CoTPP}-\mathrm{L}$ clusters and of the $\mathrm{Co}-\mathrm{L}$ and $\mathrm{Au}-\mathrm{Co}$ bonds; all the energy terms are in $\mathrm{eV}$.

Author Contributions: Methodology, analysis, investigation, and writing—original draft preparation, S.C. and M.C.; review and editing, S.C., I.C., V.F., L.F. and M.C.; funding acquisition, S.C. and M.C. All authors have read and agreed to the published version of the manuscript.

Funding: This research was supported by the University of Padova (Grant P-DISC \#CARL-SID17 BIRD2017-UNIPD, Project CHIRoN).

Institutional Review Board Statement: Not applicable.

Informed Consent Statement: Not applicable.

Data Availability Statement: All data have been illustrated in the manuscript and in the Supplementary Materials.

Acknowledgments: The Computational Chemistry Community $\left(C_{3} P\right)$ of the University of Padova is kindly acknowledged.

Conflicts of Interest: All authors of this manuscript directly participated in the planning, execution, and analysis of this study. The contents of this manuscript have not been copyrighted or published previously and are not currently under consideration for publication elsewhere. The contents of this manuscript will not be copyrighted, submitted, or published elsewhere after acceptance by Nanomaterials.

\section{References}

1. Brand, H.; Arnold, J. Recent developments in the chemistry of early transition metal porphyrin compounds. Coord. Chem. Rev. 1995, 140, 137-168. [CrossRef]

2. Gounden, D.; Nombona, N.; van Zyl, W.E. Recent advances in phthalocyanines for chemical sensor, non-linearoptics (NLO) and energy storage applications. Coord. Chem. Rev. 2020, 420, 213359. [CrossRef]

3. Rakow, N.A.; Suslick, K.S. A colorimetric sensor array for odour visualization. Nature 2000, 406, 710-713. [CrossRef] [PubMed]

4. Beyene, B.B.; Hung, C.H. Recent progress on metalloporphyrin-based hydrogen evolution catalysis. Coord. Chem. Rev. 2020, 410, 213234. [CrossRef]

5. Singh, R.; Mukherjee, A. Metalloporphyrin Catalyzed C-H Amination. ACS Catal. 2019, 9, 3604-3617. [CrossRef]

6. Sorokin, A.B. Phthalocyanine Metal Complexes in Catalysis. Chem. Rev. 2013, 113, 8152-8192. [CrossRef]

7. Bartolomé, J.; Monton, C.; Schuller, I.K. Magnetism of Metal Phthalocyanines. In Molecular Magnets; Bartolomé, J., Luis, F., Fernández, J., Eds.; Springer: Berlin, Heidelberg, Germany, 2014; pp. 221-245.

8. Aykanat, A.; Meng, Z.; Benedetto, G.; Mirica, K.A. Molecular Engineering of Multifunctional Metallophthalocyanine- Containing Framework Materials. Chem. Mater. 2020, 32, 5372-5409. [CrossRef]

9. Barraud, C.; Seneor, P.; Mattana, R.; Fusil, S.; Bouzehouane, K.; Deranlot, C.; Graziosi, P.; Hueso, L.; Bergenti, I.; Dediu, V.; et al. Unravelling the role of the interface for spin injection into organic semiconductors. Nat. Phys. 2010, 6, 615-620. [CrossRef] 
10. Zhou, J.; Sun, Q. Magnetism of Phthalocyanine-Based Organometallic Single Porous Sheet. J. Am. Chem. Soc. 2011, 133, 15113-15119. [CrossRef]

11. Paolesse, R.; Nardis, S.; Monti, D.; Stefanelli, M.; Di Natale, C. Porphyrinoids for Chemical Sensor Applications. Chem. Rev. 2017, 117, 2517-2583. [CrossRef]

12. Drain, C.M.; Varotto, A.; Radivojevic, I. Self-Organized Porphyrinic Materials. Chem. Rev. 2009, 109, 1630-1658. [CrossRef]

13. Liu, Z.; Yasseri, A.A.; Lindsey, J.S.; Bocian, D.F. Molecular memories that survive silicon device processing and real-world operation. Science 2003, 302, 1543-1545. [CrossRef]

14. Wende, H.; Bernien, M.; Luo, J.; Sorg, C.; Ponpandian, N.; Kurde, J.; Miguel, J.; Piantek, M.; Xu, X.; Eckhold, P.; et al. Substrateinduced magnetic ordering and switching of iron porphyrin molecules. Nat. Mater. 2007, 6, 516-520. [CrossRef]

15. Cojocariu, I.; Carlotto, S.; Sturmeit, H.M.; Zamborlini, G.; Cinchetti, M.; Cossaro, A.; Verdini, A.; Floreano, L.; Jugovac, M.; Puschnig, P.; et al. Ferrous to Ferric Transition in Fe-Phthalocyanine Driven by $\mathrm{NO}_{2}$ Exposure. Chem. A Eur. J. 2021, 27, $3526-3535$. [CrossRef]

16. Carlotto, S.; Sambi, M.; Sedona, F.; Vittadini, A.; Bartolomé, J.; Bartolomé, F.; Casarin, M. L2,3-edges absorption spectra of a 2D complex system: A theoretical modelling. Phys. Chem. Chem. Phys. 2016, 18, 28110-28116. [CrossRef]

17. Cojocariu, I.; Carlotto, S.; Zamborlini, G.; Jugovac, M.; Schio, L.; Floreano, L.; Casarin, M.; Feyer, V.; Schneider, C. Reversible redox reactions in metal-supported porphyrin: The role of spin and oxidation state. J. Mater. Chem. C 2021, 9, 12559-12565. [CrossRef]

18. Chang, M.H.; Kim, N.Y.; Chang, Y.H.; Lee, Y.; Jeon, U.S.; Kim, H.; Kim, Y.H.; Kahng, S.J. O ${ }_{2}, \mathrm{NO}_{2}$ and $\mathrm{NH}_{3}$ coordination to Co-porphyrin studied with scanning tunneling microscopy on Au(111). Nanoscale 2019, 11, 8510-8517. [CrossRef]

19. Flechtner, K.; Kretschmann, A.; Steinrück, H.P.; Gottfried, J.M. NO-Induced Reversible Switching of the Electronic Interaction between a Porphyrin-Coordinated Cobalt Ion and a Silver Surface. J. Am. Chem. Soc. 2007, 129, 12110-12111. [CrossRef]

20. Gottfried, J.M.; Marbach, H. Surface-Confined Coordination Chemistry with Porphyrins and Phthalocyanines: Aspects of Formation, Electronic Structure, and Reactivity. Zeitschrift fur Phys. Chem. 2009, 223, 53-74. [CrossRef]

21. Chang, M.H.; Chang, Y.H.; Kim, N.Y.; Kim, H.; Lee, S.H.; Choi, M.S.; Kim, Y.H.; Kahng, S.J. Tuning and sensing spin interactions in Co-porphyrin/Au with $\mathrm{NH}_{3}$ and $\mathrm{NO}_{2}$ binding. Phys. Rev. B 2019, 100, 245406. [CrossRef]

22. Ballav, N.; Wäckerlin, C.; Siewert, D.; Oppeneer, P.M.; Jung, T.A. Emergence of On-Surface Magnetochemistry. J. Phys. Chem. Lett. 2013, 4, 2303-2311. [CrossRef]

23. Wäckerlin, C.; Chylarecka, D.; Kleibert, A.; Müller, K.; Iacovita, C.; Nolting, F.; Jung, T.A.; Ballav, N. Controlling spins in adsorbed molecules by a chemical switch. Nat. Commun. 2010, 1, 1-7. [CrossRef]

24. Wäckerlin, C.; Tarafder, K.; Siewert, D.; Girovsky, J.; Hählen, T.; Iacovita, C.; Kleibert, A.; Nolting, F.; Jung, T.A.; Oppeneer, P.M.; et al. On-surface coordination chemistry of planar molecular spin systems: Novel magnetochemical effects induced by axial ligands. Chem. Sci. 2012, 3, 3154-3160. [CrossRef]

25. Hieringer, W.; Flechtner, K.; Kretschmann, A.; Seufert, K.; Auwärter, W.; Barth, J.V.; Görling, A.; Steinrück, H.P.; Gottfried, J.M. The Surface Trans Effect: Influence of Axial Ligands on the Surface Chemical Bonds of Adsorbed Metalloporphyrins. J. Am. Chem. Soc. 2011, 133, 6206-6222. [CrossRef] [PubMed]

26. Houwaart, T.; Le Bahers, T.; Sautet, P.; Auwärter, W.; Seufert, K.; Barth, J.V.; Bocquet, M.L. Scrutinizing individual CoTPP molecule adsorbed on coinage metal surfaces from the interplay of STM experiment and theory. Surf. Sci. 2015, 635, 108-114. [CrossRef]

27. Bertoncello, R.; Bettinelli, M.; Casarin, M.; Gulino, A.; Tondello, E.; Vittadini, A. Zn ${ }_{4} \mathrm{O}$ (acetate) 6 , a Well-Tailored Molecular Model of $\mathrm{ZnO}$. An Experimental and Theoretical Investigation of the Electronic Structure of $\mathrm{Zn}_{4} \mathrm{O}$ (acetate) ${ }_{6}$ and $\mathrm{ZnO}$ by Means of UV and X-ray Photoelectron Spectroscopies and First Principle Local Density Molecular Cluster Calculations. Inorg. Chem. 1992, 31, 1558-1565.

28. Weber-Bargioni, A.; Auwärter, W.; Klappenberger, F.; Reichert, J.; Lefrançois, S.; Strunskus, T.; Wöll, C.; Schiffrin, A.; Pennec, Y.; Barth, J.V. Visualizing the Frontier Orbitals of a Conformationally Adapted Metalloporphyrin. ChemPhysChem 2008, 9, 89-94. [CrossRef] [PubMed]

29. Donovan, P.; Robin, A.; Dyer, M.S.; Persson, M.; Raval, R. Unexpected Deformations Induced by Surface Interaction and Chiral Self-Assembly of $\mathrm{Co}^{\mathrm{II}}$-Tetraphenylporphyrin (Co-TPP) Adsorbed on $\mathrm{Cu}(110)$ : A Combined STM and Periodic DFT Study. Chem. A Eur. J. 2010, 16, 11641-11652. [CrossRef]

30. Lukasczyk, T.; Flechtner, K.; Merte, L.R.; Jux, N.; Maier, F.; Gottfried, J.M.; Steinrück, H.P. Interaction of Cobalt(II) Tetraarylporphyrins with a $\operatorname{Ag}(111)$ Surface Studied with Photoelectron Spectroscopy. J. Phys. Chem. C 2007, 111, 3090-3098. [CrossRef]

31. Wechsler, D.; Franke, M.; Tariq, Q.; Zhang, L.; Lee, T.L.; Thakur, P.K.; Tsud, N.; Bercha, S.; Prince, K.C.; Steinrück, H.P.; et al. Adsorption Structure of Cobalt Tetraphenylporphyrin on Ag(100). J. Phys. Chem. C 2017, 121, 5667-5674. [CrossRef]

32. Barlow, D.E.; Scudiero, L.; Hipps, K.W. Scanning Tunneling Microscopy Study of the Structure and Orbital-Mediated Tunneling Spectra of Cobalt(II) Phthalocyanine and Cobalt(II) Tetraphenylporphyrin on Au(111): Mixed Composition Films. Langmuir 2004, 20, 4413-4421. [CrossRef]

33. Chang, Y.H.; Kim, H.; Kahng, S.J.; Kim, Y.H. Axial coordination and electronic structure of diatomic $\mathrm{NO}, \mathrm{CO}$, and $\mathrm{O}_{2}$ molecules adsorbed onto Co-tetraphenylporphyrin on $\mathrm{Au}(111), \mathrm{Ag}(111)$, and $\mathrm{Cu}(111)$ : A density-functional theory study. Dalton Trans. 2016, 45, 16673-16681. [CrossRef]

34. Te Velde, G.; Bickelhaupt, F.M.; Baerends, E.J.; Fonseca Guerra, C.; van Gisbergen, S.J.A.; Snijders, J.G.; Ziegler, T. Chemistry with ADF. J. Comput. Chem. 2001, 22, 931-967. [CrossRef]

35. ADF2014; SCM. Theoretical Chemistry. Available online: http://www.scm.com (accessed on 7 January 2022) 
36. Van Lenthe, E.; Ehlers, A.; Baerends, E.J. Geometry optimizations in the zero order regular approximation for relativistic effects. J. Chem. Phys. 1999, 110, 8943-8953. [CrossRef]

37. Van Lenthe, E.; Baerends, E.J.; Snijders, J.G. Relativistic regular two-Component Hamiltonians. J. Chem. Phys. 1993, 99, 4597-4610. [CrossRef]

38. Perdew, J.P. Density-functional approximation for the correlation energy of the inhomogeneous electron gas. Phys. Rev. B 1986, 33, 8822-8824. [CrossRef]

39. Becke, A.D. Density-functional exchange-energy approximation with correct asymptotic behavior. Phys. Rev. A 1988, 38 , 3098-3100. [CrossRef]

40. Van Lenthe, E.; Baerends, E.J. Optimized Slater-type basis sets for the elements 1-118. J. Comput. Chem. 2003, 24, 1142-1156. [CrossRef]

41. Carlotto, S.; Sambi, M.; Sedona, F.; Vittadini, A.; Casarin, M. A Theoretical Study of the Occupied and Unoccupied Electronic Structure of High- and Intermediate-Spin Transition Metal Phthalocyaninato (Pc) Complexes: VPc, CrPc, MnPc, and FePc. Nanomaterials 2021, 11, 54. [CrossRef]

42. Carlotto, S.; Sambi, M.; Rancan, M.; Casarin, M. Theoretical Investigation of the Electronic Properties of Three Vanadium Phthalocyaninato (Pc) Based Complexes: PcV, PcVO, and PcVI. Inorg. Chem. 2018, 57, 1859-1869. [CrossRef]

43. Mangione, G.; Carlotto, S.; Sambi, M.; Ligorio, G.; Timpel, M.; Vittadini, A.; Nardi, M.V.; Casarin, M. Electronic structures of CuTPP and CuTPP(F) complexes. A combined experimental and theoretical study I. Phys. Chem. Chem. Phys. 2016, 18, 18727-18738. [CrossRef]

44. Mangione, G.; Sambi, M.; Carlotto, S.; Vittadini, A.; Ligorio, G.; Timpel, M.; Pasquali, L.; Giglia, A.; Nardi, M.V.; Casarin, M. Electronic structures of CuTPP and CuTPP(F) complexes. A combined experimental and theoretical study II. Phys. Chem. Chem. Phys. 2016, 18, 24890-24904. [CrossRef]

45. Nardi, M.V.; Detto, F.; Aversa, L.; Verucchi, R.; Salviati, G.; Iannotta, A.; Casarin, M. Electronic properties of CuPc and H2Pc: An experimental and theoretical study. Phys. Chem. Chem. Phys. 2013, 15, 12864-12881. [CrossRef]

46. Ziegler, T.; Rauk, A. On the calculation of bonding energies by the Hartree Fock Slater method. Theor. Chim. Acta 1977, 46, 1-10. [CrossRef]

47. Casarin, M.; Forrer, D.; Garau, F.; Pandolfo, L.; Pettinari, C.; Vittadini, A. Density Functional Theory Study of the Binding Capability of Tris(pyrazol-1-yl)methane toward Cu(I) and Ag(I) Cations. J. Phys. Chem. A 2008, 112, 6723-6731. [CrossRef]

48. Auwärter, W.; Seufert, K.; Klappenberger, F.; Reichert, J.; Weber-Bargioni, A.; Verdini, A.; Cvetko, D.; Dell'Angela, M.; Floreano, L.; Cossaro, A.; et al. Site-specific electronic and geometric interface structure of Co-tetraphenyl-porphyrin layers on Ag(111). Phys. Rev. B 2010, 81, 245403. [CrossRef]

49. Schwarz, M.; Garnica, M.; Duncan, D.A.; Paz, A.P.; Ducke, J.; Deimel, P.S.; Thakur, P.K.; Lee, T.-L.; Rubio, A.; Barth, J.V.; et al Adsorption Conformation and Lateral Registry of Cobalt Porphine on Cu(111). J. Phys. Chem. C 2018, 122, 5452-5461. [CrossRef]

50. Duncan, D.A.; Casado Aguilar, P.; Paszkiewicz, M.; Diller, K.; Bondino, F.; Magnano, E.; Klappenberger, F.; Píš, I.; Rubio, A.; Barth, J.V.; et al. Local adsorption structure and bonding of porphine on $\mathrm{Cu}(111)$ before and after self-metalation. J. Chem. Phys. 2019, 150, 094702. [CrossRef]

51. Buimaga-Iarinca, L.; Morari, C. The effect of translation on the binding energy for transition-metal porphyrines adsorbed on $\operatorname{Ag}(111)$ surface. Beilstein J. Nanotechnol. 2019, 10, 706-717. [CrossRef]

52. Eaton, S.S.; Eaton, G.R. Magnetic susceptibility of porphyrins. Inorg. Chem. 1980, 19, 1095-1096. [CrossRef]

53. Douglas, B.E.; Hollingsworth, C.A. Symmetry in Bonding and Spectra: An Introduction; Academic Press: Orlando, FL, USA, 1985.

54. Li, J.; Schreckenbach, G.; Ziegler, T. A Reassessment of the First Metal-Carbonyl Dissociation Energy in M(CO) ${ }_{4}(\mathrm{M}=\mathrm{Ni}, \mathrm{Pd}, \mathrm{Pt})$, $\mathrm{M}(\mathrm{CO})_{5}(\mathrm{M}=\mathrm{Fe}, \mathrm{Ru}, \mathrm{Os})$, and $\mathrm{M}(\mathrm{CO})_{6}(\mathrm{M}=\mathrm{Cr}, \mathrm{Mo}, \mathrm{W})$ by a Quasirelativistic Density Functional Method. J. Am. Chem. Soc. 1995, 117, 486-494. [CrossRef]

55. Hirshfeld, F.L. Bonded-atom fragments for describing molecular charge densities. Theor. Chim. Acta 1977, 44, 129-138. [CrossRef]

56. Nalewajski, R.F.; Mrozek, J. Modified valence indices from the two-particle density matrix. Int. J. Quantum Chem. 1994, 51, 187-200. [CrossRef]

57. Nalewajski, R.F.; Mrozek, J.; Formosinho, S.J.; Varandas, A.J.C. Quantum mechanical valence study of a bond-breaking-bond forming process in triatomic systems. Int. J. Quantum Chem. 1994, 52, 1153-1176. [CrossRef]

58. Nalewajski, R.F.; Mrozek, J. Hartree-Fock difference approach to chemical valence: Three-electron indices in UHF approximation. Int. J. Quantum Chem. 1996, 57, 377-389. [CrossRef]

59. Nalewajski, R.F.; Mrozek, J.; Mazur, G. Quantum chemical valence indices from the one-determinantal difference approach. Can. J. Chem. 1996, 74, 1121-1130. [CrossRef]

60. Nalewajski, R.F.; Mrozek, J.; Michalak, A. Two-electron valence indices from the Kohn-Sham orbitals. Int. J. Quantum Chem. 1997, 61, 589-601. [CrossRef]

61. Nalewajski, R.F.; Mrozek, J.; Michalak, A. Exploring bonding patterns of molecular systems using quantum mechanical bond multiplicities. Polym. J. Chem. 1998, 72, 1779-1791.

62. Michalak, A.; DeKock, R.L.; Ziegler, T. Bond Multiplicity in Transition-Metal Complexes: Applications of Two-Electron Valence Indices. J. Phys. Chem. A 2008, 112, 7256-7263. [CrossRef]

63. Haller, K.J.; Enemark, J.H. Structural Chemistry of the $\{\text { CoNO }\}^{8}$ Group. III. ${ }^{*}$ The Structure of $N, N^{\prime}$-Ethylenebis(salicylideneiminato) nitrosylcobalt(1l), Co(NO)(Salen). Acta Cryst. 1978, B34, 102-109. [CrossRef] 
64. Kim, H.; Chang, Y.H.; Lee, S.-H.; Lim, S.; Noh, S.-K.; Kim, Y.-H.; Kahng, S.-J. Visualizing tilted binding and precession of diatomic $\mathrm{NO}$ adsorbed to Co-porphyrin on $\mathrm{Au}(111)$ using scanning tunneling microscopy. Chem. Sci. 2014, 5, 2224-2229. [CrossRef]

65. Perdew, J.P.; Burke, K.; Ernzerhof, M. Generalized Gradient Approximation Made Simple. Phys. Rev. Lett. 1996, 77, 3865-3868. [CrossRef]

66. Rousseau, R.; Ozarowski, A.; Aroca, R.; de Soares, L.A., II; Trsic, M. The electronic structure of metalated phthalocyanine-NO 2 adducts. J. Mol. Struct. 1994, 317, 287-297. [CrossRef]

67. Greenwood, N.N.; Earnshaw, A. Chemistry of the Elements, 2nd ed.; Butterworth-Heinemann: Cambridge, UK, 1998.

68. Sharafeldin, I.M.; Allam, N.K. DFT insights into the electronic properties and adsorption of $\mathrm{NO}_{2}$ on metal-doped carbon nanotubes for gas sensing applications. New J. Chem. 2017, 41, 14936-14944. [CrossRef]

69. Rodley, G.A.; Robinson, W.T. Structure of a Monomeric Oxygen-carrying Complex. Nature 1972, 235, 438-439. [CrossRef]

70. Melamud, E.; Silver, B.L.; Dori, Z. Electron Paramagnetic Resonance of Mononuclear Cobalt Oxygen Carriers Labeled with Oxygen-17. J. Am. Chem. Soc. 1974, 96, 4690-4692. [CrossRef]

71. Gall, R.S.; Rogers, J.F.; Schaefer, W.P.; Christoph, G.G. The structure of a monomeric oxygen carrying cobalt complex: Dioxygen$\mathrm{N}, \mathrm{N}^{\prime}$-(1,1,2,2-tetramethyl)ethylenebis(3-tert-butylsalicylideniminato)(1-benzylimidazole)cobalt(II). J. Am. Chem. Soc. 1976, 98, 5135-5144. [CrossRef]

72. Gall, R.S.; Schaefer, W.P. Preparation and structural characterization of a monomeric dioxygen adduct of $\left(\mathrm{N}^{\prime}, \mathrm{N}^{\prime}-(1,1,2,2-\right.$ tetramethylethylene)bis(salicylideniminato))-(1-benzylimidazole)cobalt(II). Inorg. Chem. 1976, 15, 2758-2763. [CrossRef]

73. Avdeef, A.; Schaefer, W.P. Reversible oxygen carriers. The synthesis and low temperature (-171.degree.) structure of an unstable monomeric dioxygen adduct of N,N'-(1,1,2,2-tetramethyl)ethylenebis(3-fluorosalicylideniminato)(1-methylimidazole)cobalt(II), Co(3-F-Saltmen)(1-Me-Imid)(O2).2Me2CO. J. Am. Chem. Soc. 1976, 98, 5153-5159.

74. Tovrog, B.S.; Kitko, D.J.; Drago, R.S. Nature of the Bound O2 in a Series of Cobalt Dioxygen Adducts. J. Am. Chem. Soc. 1976, 98, 5144-5153. [CrossRef]

75. Schaefer, W.P.; Huie, B.T.; Kurilla, M.G.; Ealick, S.E. Oxygen-carrying cobalt complexes. 10. Structures of N,N'-ethylenebis(3-tertbutylsalicyliden iminato)cobalt (II) and its monomeric dioxygen adduct. Inorg. Chem. 1980, 19, 340-344. [CrossRef]

76. Seufert, K.; Auwärter, W.; Barth, J.V. Discriminative Response of Surface-Confined Metalloporphyrin Molecules to Carbon and Nitrogen Monoxide. J. Am. Chem. Soc. 2010, 132, 18141-18146. [CrossRef] 